\author{
Military Technical College \\ Kobry Elkobbah, \\ Cairo, Egypt
}

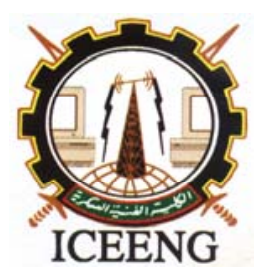

\author{
$5^{\text {th }}$ International Conference \\ on Electrical Engineering \\ ICEENG 2006
}

\title{
GEOMETRIC CORRECTION OF REMOTE SENSING SATELLITE DIGITAL IMAGES USING MAPPING POLYNOMIAL OF DIFFERENT ORDERS
}

\author{
Fawzy ELtohamy Hassan*, Ph.D. Gouda Ismail Salama*, Ph.D. \\ Esam Hassan Hamza*, B.Sc. H. A. Hussien*, Ph.D.
}

\section{Abstract:}

All remote sensing imagery, from satellites, is inherently subjected to geometric distortions. Therefore geometric corrections, as preprocessing operations, are normally required prior to imagery analysis and extraction of information.

This paper conducts geometric correction procedure of sample of raw satellite images using georeferenced images (image-to-image registration) of the same area. In this procedure, many well-distributed ground control points (GCPs) pairs (from both images) are identified. Then a proper transformation polynomial is applied to map the original image GCPs coordinates into the new georeferenced image GCPs coordinates. A resampling process is carried out to recalculate the gray level values for pixels in the transformed output image (new pixels locations) based on pixel values in the input image. Also, this paper presents an analysis study of the effect of variation of the number of GCPs and the order of the mapping polynomials on the accuracy of geometric correction process. The Root Mean Square Error (RMS), at the selected GCPs, are calculated and used as a measure of accuracy of the obtained results.

Keyword: Remote sensing satellite imagery, Geometric correction, Image registration, Ground control points, Resampling.

\section{1- Introduction:}

All remote sensing images, from satellites, are subjected to geometric distortions. Therefore geometric corrections, as preprocessing operations, are normally required prior to imagery analysis and extraction of information.

Geometric distortion in an image means that the image features positions do not accurately relate to scene on ground or on map positions.

The geometric distortions may be due to several sources [1], including: The motion of the scanning system; the motion of the platform; the platform altitude, attitude, and velocity variations; the terrain relief; the Earth curvature and rotation of the Earth around its axis during imaging acquisition.

Geometric distortions can be classified into two types [2], [3]:

*Egyptian Armed Forces 
1. Systematic (predictable) distortions. A highly systematic source of distortion involved in imaging from satellites is the eastward rotation of the earth beneath the satellite during imaging acquisition.

2. Non-systematic (random / unpredictable) distortion

Geometric corrections are intended to compensate for these distortions so that the geometric representation of the imagery will be as close as possible to the real world.

There are 2 main approaches [2], [3], for correction of the various types of geometric distortions.

1- Systematic distortions can be corrected by applying formulas derived by modeling the sources of the distortions mathematically and use these models to establish correction formulae. These modeling techniques require priori knowledge about the orbit parameters; the nature and the magnitude of the sources of distortion during the scene acquisition time. Sometimes these priori information is not available and consequently these techniques cannot be applied.

2- Random distortions and residual unknown systematic distortions are corrected by establishing mathematical relations between the coordinates of pixels in an image and the corresponding coordinates of those points on the ground. These relations can be used to correct the image geometry irrespective of prior information about the source and type of distortion.

The second approach is the most commonly used and it is independent of the platform used for image acquisition. This approach involves two steps. First step is registration process. It involves identifying raw image coordinates (i.e. row, column) of several clearly discernible points, called ground control points (GCPs), in the distorted image, and map them either to their true positions in ground coordinates (e.g. latitude, longitude) measured from a map (image-tomap registration), or to georeferenced image (corrected before), coordinates of corresponding points (image-to-image registration), through to mathematical transformation, that will convert the raw image coordinates into the desired coordinates [2]. The second step is the resampling process to recalculate the gray level values for pixels in the transformed output image based on pixel values in the input (uncorrected) image. There are three common methods for resampling: nearest neighbor, bilinear interpolation, and cubic convolution [4].

Many studies have been carried out on the geometric correction of satellite images, either using the first approach, [5], [6], [7], [8], [9], or using the second approach [10], [11], [12], [13].

\section{2- Satellite images data under study}

In this paper, the geometric correction process is applied on a sample of three raw (sourceuncorrected) satellite images, (named imagel to image3). These three images are acquired in 1999 by remote sensing satellite LANDSAT 5 . They are characterized by the following:

1- Image1, image2 and image 3 represent the areas of Banisuwaf city, East and West sides of the River Nile, AlGezah city (Egypt), respectively. 
2- Image 1, image 2 and image 3 are acquired in red $(0.6-0.7 \mu \mathrm{m})$, green $(0.5-0.6 \mu \mathrm{m})$, and blue $(0.4-0.5 \mu \mathrm{m})$ spectral bands respectively.

3- The size of each of image1, image 2 , and image 3 , is $417 \times 460$ pixels.

The three reference (pre-corrected) images, of the same area, size, and imaging band, are used to be registered with the source images. The reference images are acquired in 1999 by LANDSAT 5. They were geometrically corrected using maps (image-to- map) registration.

\section{3- Geometric correction process using mapping polynomials}

As, mentioned before the second approach of geometric corrections depends on establishing mathematical relationships (mapping function) between the addresses of pixels in the distorted image and the corresponding coordinates of those points on the ground via a map or precorrected image, represented generally as follows:

Where:

$$
\begin{aligned}
& \mathrm{u}=\mathrm{f}(\mathrm{x}, \mathrm{y}) \\
& \mathrm{v}=\mathrm{g}(\mathrm{x}, \mathrm{y})
\end{aligned}
$$

$\mathrm{x}, \mathrm{y} \ldots .$. the location of points in the reference image (or map in image-to-map registration)

$\mathrm{u}, \mathrm{v} \ldots$ the location of pixels in the source (distorted) input image

$\mathrm{f}, \mathrm{g}$.....the pair of mapping functions.

In fact explicit forms for the mapping functions (1), are not known therefore they generally chosen as simple polynomials of different degrees. The polynomial equations for a $t$-degree transformation take this form [4]:

Where:

$$
\begin{aligned}
& u=\sum_{i=0}^{t} \sum_{j=0}^{i} a_{k} \times x^{i-j} \times y^{j} \\
& v=\sum_{i=0}^{t} \sum_{j=0}^{i} b_{k} \times x^{i-j} \times y^{j}
\end{aligned}
$$

$\mathrm{u}$ and $\mathrm{v}$ are source coordinates (distorted image).

$\mathrm{x}_{\text {and }} \mathrm{y}$ are reference coordinates .

$\mathrm{t}$ is the order (degree) of the polynomial

$a_{k}$ and $b_{k}$ are the polynomial coefficients

The minimum number of selected GCPs depends on the polynomial order. The relations between the order of the polynomials; the minimum required number of GCPs; and number of coefficients of the used polynomials, are given by [4].

$$
N=\frac{(t+1)(t+2)}{2}
$$




$$
M=(t+1)(t+2)
$$

Where:

$\mathrm{N} \quad$ minimum number of GCPs

$\mathrm{t}$ order of the polynomial

$\mathrm{M}$ number of coefficients

In this work the applied polynomials are of first upto fifth order. Table 1. gives corresponding number of unknown coefficients and the minimum required number of GCPs

Table 1. Order of polynomials, number of unknown coefficients and corresponding minimum number of GCPs

\begin{tabular}{|c|c|c|}
\hline Polynomial Order & Minimum No. of GCPs & Number of coefficients \\
\hline First & 3 & 6 \\
\hline Second & 6 & 12 \\
\hline Third & 10 & 20 \\
\hline Fourth & 15 & 30 \\
\hline Fifth & 21 & 42 \\
\hline
\end{tabular}

\section{4- Experimental work}

The geometric correction process is applied on the selected sample of three raw images, by the aid of Erdas Imagine $8.5 \mathrm{SW}$, using the image-to-image registration, and polynomial model of $1^{\text {st }}, 2^{\text {nd }}, 3^{\text {rd }}, 4^{\text {th }}$, and $5^{\text {th }}$ order. The bilinear interpolation resampling method is used to calculate the pixels gray level values of the rectified output image in every case. The accuracy of the correction process is evaluated by calculating the RMS error for every GCP at different cases. The RMS error is the difference between the desired output coordinate for a GCP and the actual output coordinate for the same point, when the point is transformed with the geometric transformation. RMS error in X, Y directions and total (T) RMS error at the GCPs are calculated according to the following equations [4]:

$$
\begin{aligned}
& \text { RMS for } \mathrm{X}=\sqrt{\sum_{i=1}^{n}\left(\Delta X_{i}\right)^{2}} \\
& \text { RMS for } \mathrm{Y}=\sqrt{\sum_{i=1}^{n}\left(\Delta Y_{i}\right)^{2}} \\
& \text { RMS for } \mathrm{T}=\sqrt{\frac{1}{n} \sum_{i=1}^{n}\left(\Delta X^{2}{ }_{i}+\Delta Y^{2}\right)}
\end{aligned}
$$


Where:

$$
\begin{array}{ll}
\Delta \mathrm{X}_{\mathrm{i}}, \Delta \mathrm{Y}_{\mathrm{i}} & =\text { residuals of point }(\mathrm{i}) \text { in } \mathrm{X} \text { and } \mathrm{Y} \text { directions. } \\
\mathrm{T} & =\text { total RMS error } \\
\mathrm{n} & =\text { number of GCPs } \\
\mathrm{i} & =\text { GCP number }
\end{array}
$$

\section{5- Results and analysis}

Fig. 1. to Fig. 5. show the raw image1, corresponding georeferenced image, different GCPs distributions, and the output corrected image in each case.

Table 2., gives the average of RMS error of image1 at the proposed number of GCPs and order of polynomials.

Table 2. Average of RMS error of image 1

\begin{tabular}{|c|c|c|c|c|c|}
\hline \multirow{2}{*}{ No. of GCPs } & \multicolumn{5}{|c|}{ Average of RMS error of image 1 } \\
\cline { 2 - 6 } & First & Second & Third & Fourth & Fifth \\
\hline $\mathbf{4}$ & 0.070 & ----- & ----- & ----- & ----- \\
\hline $\mathbf{7}$ & 0.536 & 0.257 & ---- & ----- & ---- \\
\hline $\mathbf{1 1}$ & 0.566 & 0.353 & 0.354 & ----- & ----- \\
\hline $\mathbf{1 6}$ & 0.552 & 0.456 & 0.456 & 0.442 & ---- \\
\hline $\mathbf{2 2}$ & 0.531 & 0.424 & 0.421 & 0.413 & 1.250 \\
\hline
\end{tabular}

Fig. 6. to Fig. 10. show the raw image 2, corresponding georeferenced image, different GCPs distributions, and the output corrected image in each case.

Table 3., gives the average of RMS error of image 2 at the proposed number of GCPs and order of polynomials.

Table 3. Average of RMS error of image 2

\begin{tabular}{|c|c|c|c|c|c|}
\hline \multirow{2}{*}{ No. of GCPs } & \multicolumn{5}{|c|}{ Average of RMS error of image 2} \\
\cline { 2 - 6 } & First & Second & Third & Fourth & Fifth \\
\hline $\mathbf{4}$ & 0.057 & ----- & ---- & ----- & ---- \\
\hline $\mathbf{7}$ & 0.351 & 0.220 & ---- & ----- & ----- \\
\hline $\mathbf{1 1}$ & 0.464 & 0.382 & 0.381 & ---- & ----- \\
\hline $\mathbf{1 6}$ & 0.390 & 0.321 & 0.320 & 0.313 & ---- \\
\hline $\mathbf{2 2}$ & 0.408 & 0.368 & .0368 & 0.368 & 0.359 \\
\hline
\end{tabular}

Fig. 11. to Fig 15. show the raw image 3, corresponding georeferenced image, different GCPs distributions, and the output corrected image in each case. 
Table 4., gives the average of RMS error of image 3 at the proposed number of GCPs and order of polynomials.

Table 4. Average of RMS error of image 3

\begin{tabular}{|c|c|c|c|c|c|}
\hline \multirow{2}{*}{ No. of GCPs } & \multicolumn{5}{|c|}{ Average of RMS error of image 3 } \\
\cline { 2 - 6 } & First & Second & Third & Fourth & Fifth \\
\hline $\mathbf{4}$ & 0.163 & ----- & ----- & ----- & ----- \\
\hline $\mathbf{7}$ & 0.620 & 0.106 & ----- & ----- & ----- \\
\hline $\mathbf{1 1}$ & 0.576 & 0.340 & 0.339 & ----- & ---- \\
\hline $\mathbf{1 6}$ & 0.613 & 0.535 & 0.532 & 0.532 & ----- \\
\hline $\mathbf{2 2}$ & 0.652 & 0.570 & 0.567 & 0.572 & 0.582 \\
\hline
\end{tabular}

\section{6-Conclusion}

Fig. 16. shows that:

- The $1^{\text {st }}$ order polynomial rectification often is not considered due to small number of GCPs.

- In case of $2^{\text {nd }}$ order polynomial rectification, the average RMS errors have considerably decreased from 22, 16, 11, 7 GCPs respectively.

- In case of $3^{\text {rd }}$ order polynomial rectification, the average RMS errors have considerably decreased from 22, 16, 11 GCPs respectively.

- In case of $4^{\text {th }}$ order polynomial rectification, the average RMS errors have considerably decreased from 22, 16 GCPs respectively.

- In case of $5^{\text {th }}$ order polynomial rectification, the average RMS errors have considerably increased when using 22 GCPs.

So the higher order of polynomial rectification means higher number of GCPs leads to increase the RMS errors.

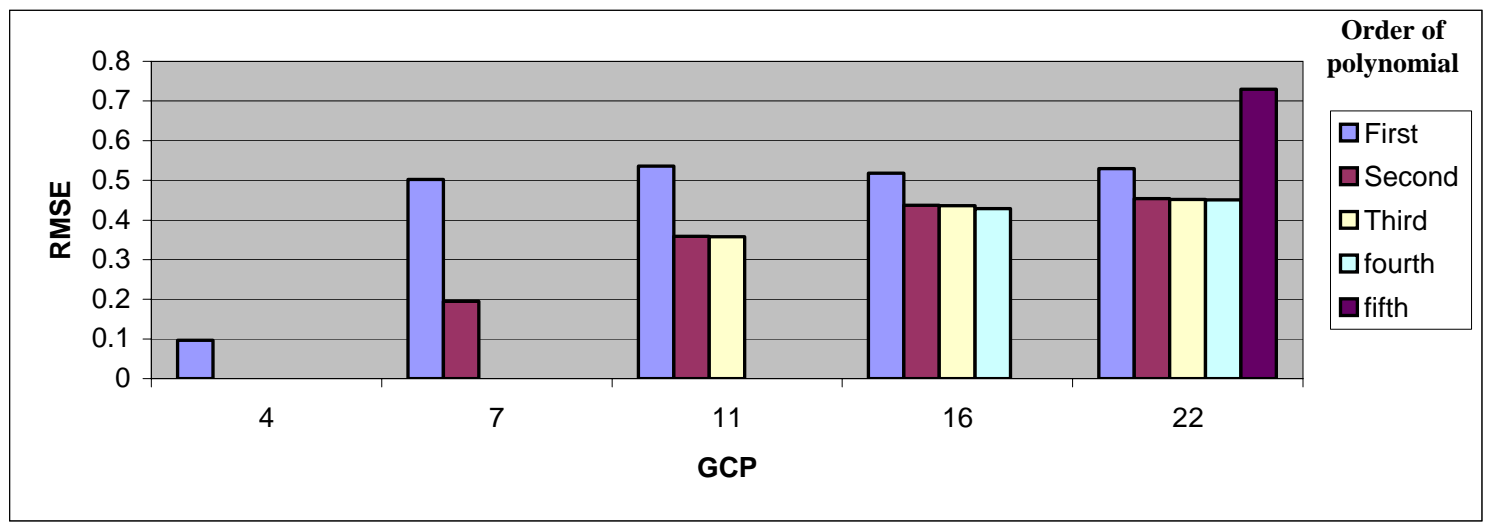

Fig. 16. The average of RMS error of all test images at each order of polynomials 


\section{7- References}

[1] Environmental Remote Sensing Forestry 753 Lab Three: Geometric Correction, (2005).

[2] John Richards \& Xiuping Jia "Remote Sensing Digital Image Analysis - An Introduction" Springer, $3^{\text {rd }}$ edition ,(1999).

[3] Thomas M. Lillesand \& Ralph W. Kiefer "Remote Sensing and Image Interpretion" $4^{\text {th }}$ edition, John Wiley \& Sons, (2000).

[4] Erdas Imagine 8.5 Field Guide, (2002).

[5] Dowmann I., and Dolloff, J., “ An evaluation of rational function for Photogrammetric restitution", International Archives of Photogrammetry and Remote Sensing, Amsterdam, The Netherlands, July 16-23, (Amsterdam, The Netherlands: GITC) Vol. 33 (B3), pp. 254- 266. (2000).

[6] El-Manadili, Y., and Novak, K.,. "Precision Rectification of spot Imagery using the direct linear

[7] Kratky, V "Rigorous Photogrammetric Processing of Spot Images at CCM Canada ", ISPRS Journal of Photogrammetry and Remote Sensing, Vol. 44, pp. 53-71. (1989).

[8] Konecny, G., Lohmann, P., Engel, H., and Kruck, E, “Evaluation of SPOT Imagery on Analytical Instruments", Photogrammetric Engineering and Remote Sensing, 53, 1223-1230., (1987).

[9] Xutong Niu, Jue Wang, Kaichang Di, Jin-Duk Lee, Ron Li,.” Geometric Modelling and Photogrammetric Processing of High Resolution Satellite Imagery" Mapping and GIS Laboratory, CEEGS, The Ohio State University. (2004).

[10] Hafez Abbas Afify,. "Planimetric Accuracy of Rectified Spot Imagery" Lecturer, Dpt. Of Transportation Engineering, Faculty of Engineering, Tanta University, Tanta, Egypt. (2002).

[11] A. M. Wu and Y. Y. Lee. "Geometric Correction of High Resolution Images Using Ground Control Points" Singapore Institute of Surveyors and Valuers (SISV); Asian Association on Remote Sensing (AARS). (2001).

[12] Yoshinari OGURO, Shoji TAKEUCHI and Yuzo SUGA, "An Improvement in Educational Tools For Geometric Correction of Satellite Images by Using DEM Shade Simulation" .(2002).

[13] Thierry Toutin,. "Review Paper: Geometric Processing of Remote Sensing Images: Models, Algorithms and Methods", Canada Centre for Remote Sensing. (2003). 


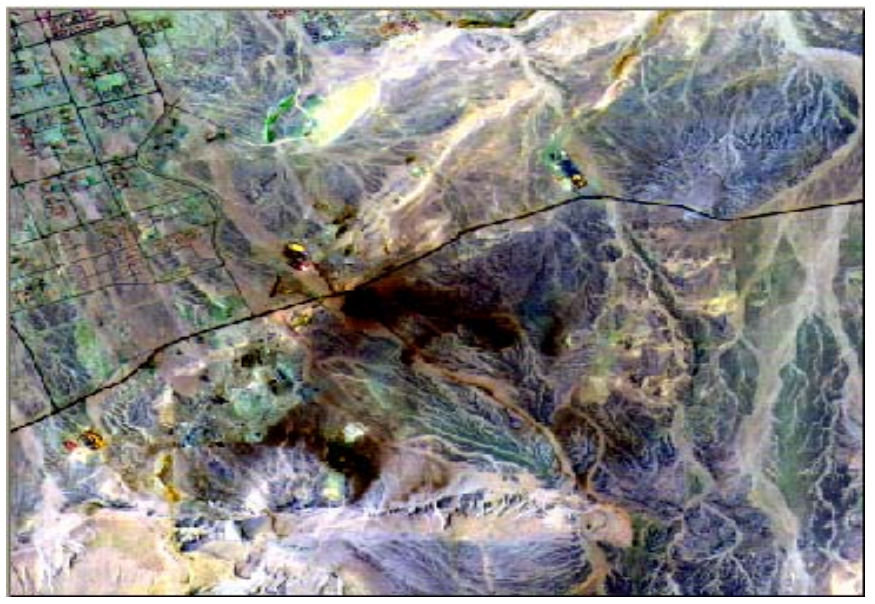

(a)

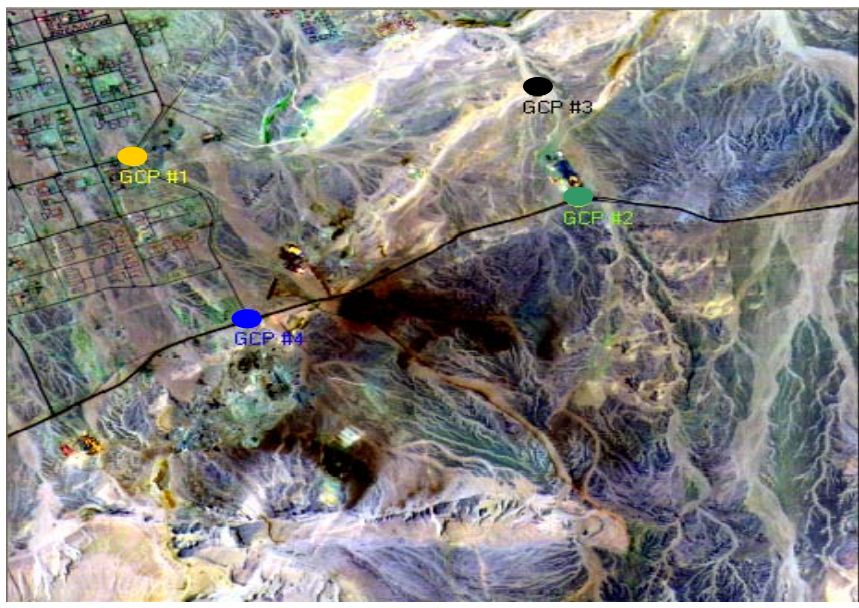

(c)

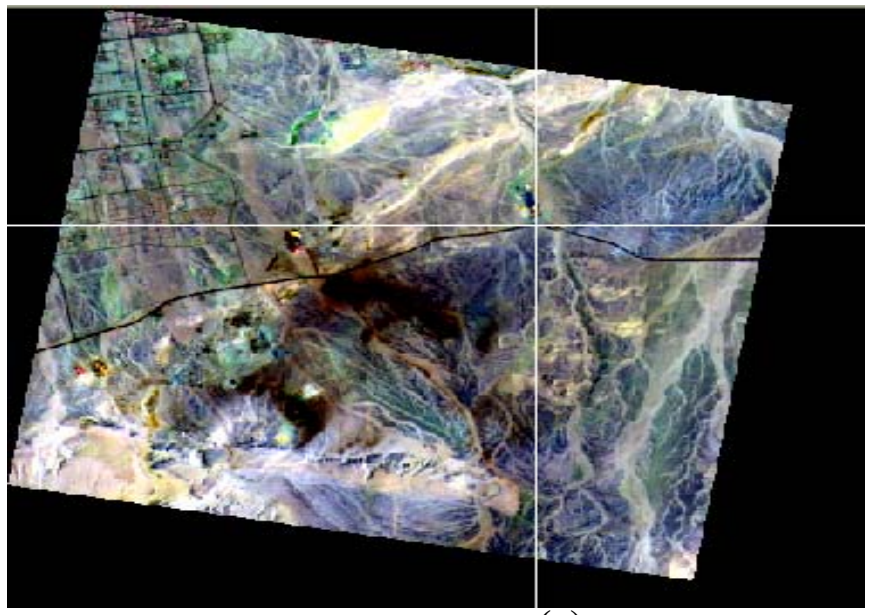

(e)

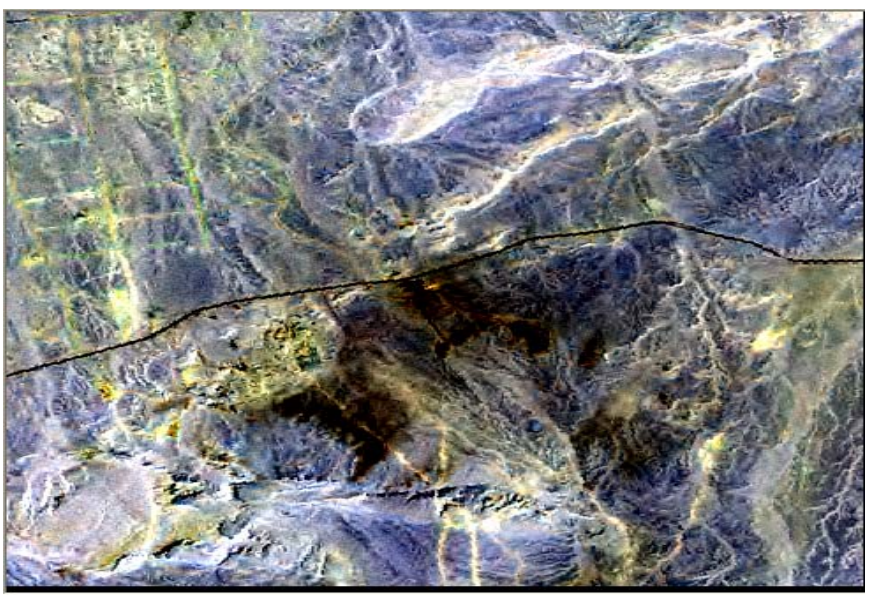

(b)

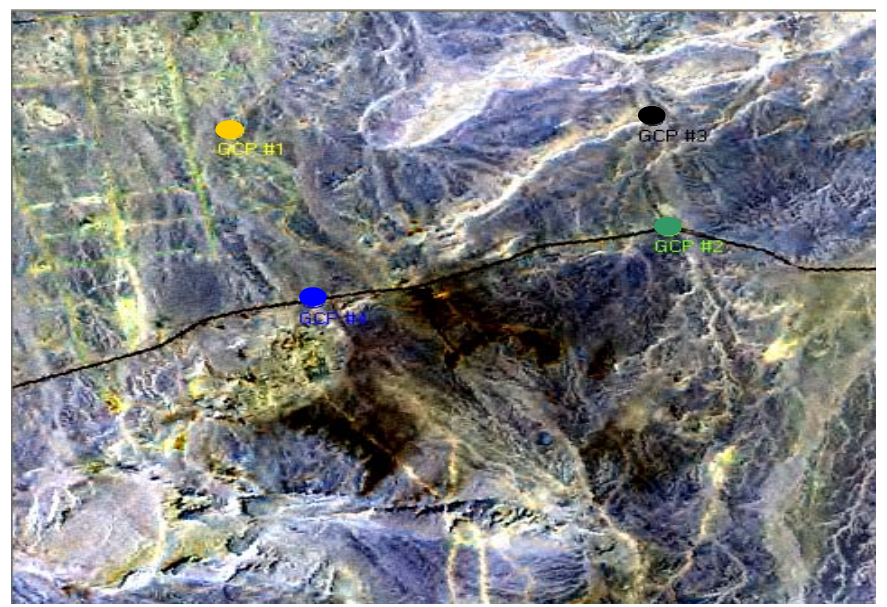

(d)

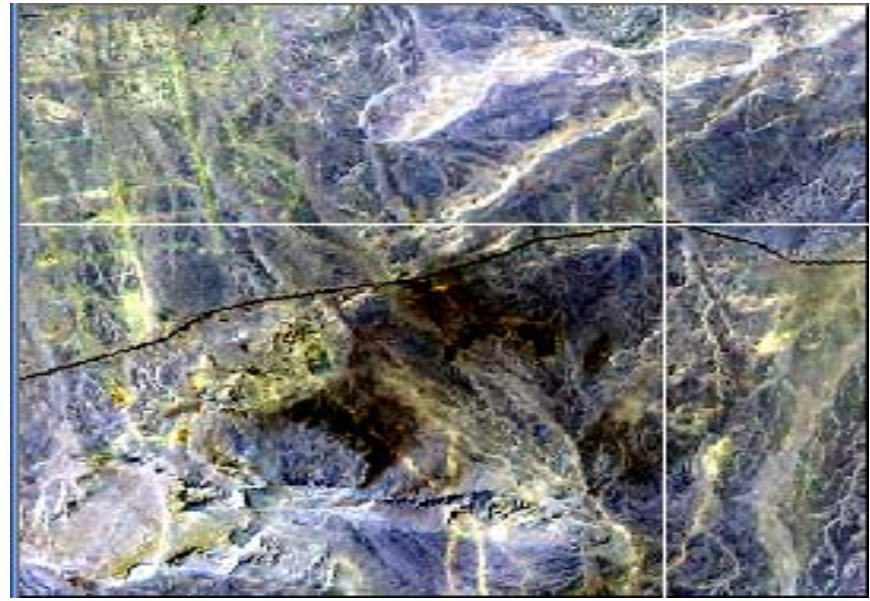

(f)

Fig. 1 a \& b - Raw image1 and its corresponding reference image, c \& d - 4 GCPs distribution on raw image1 and its reference, e \& f - Corrected image1, and its reference with link between them. 
Proceedings of the $5^{\text {th }}$ ICEENG Conference, 16-18 May, 2006

RE - 4 - 9

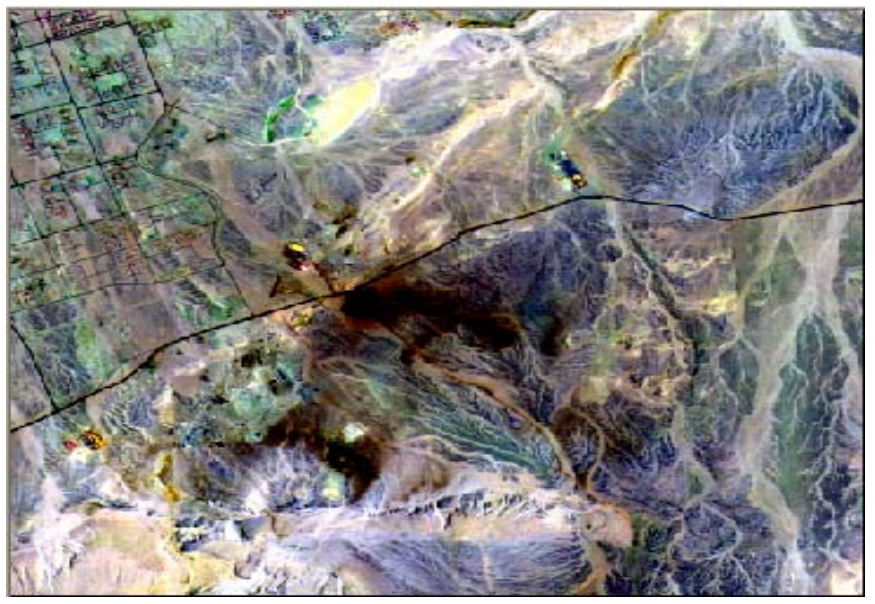

(a)

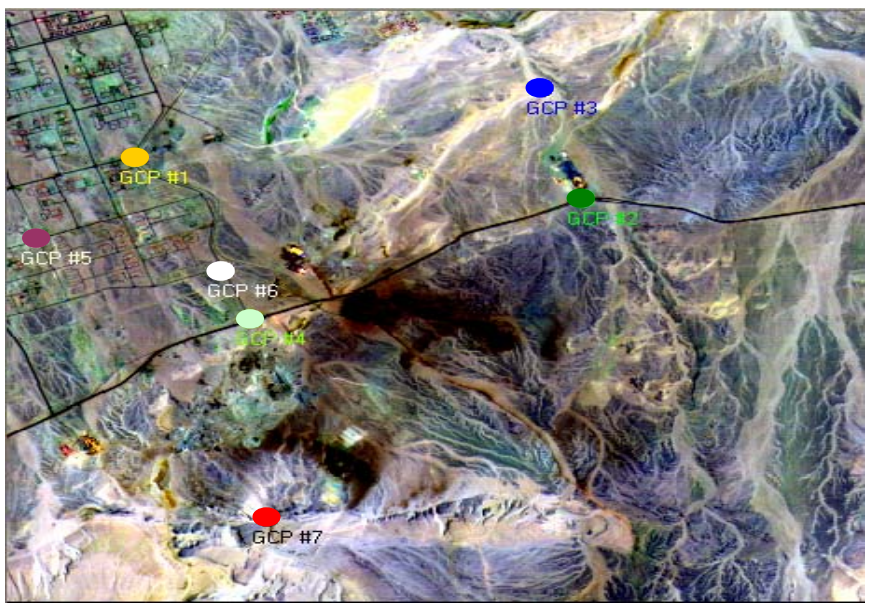

(c)

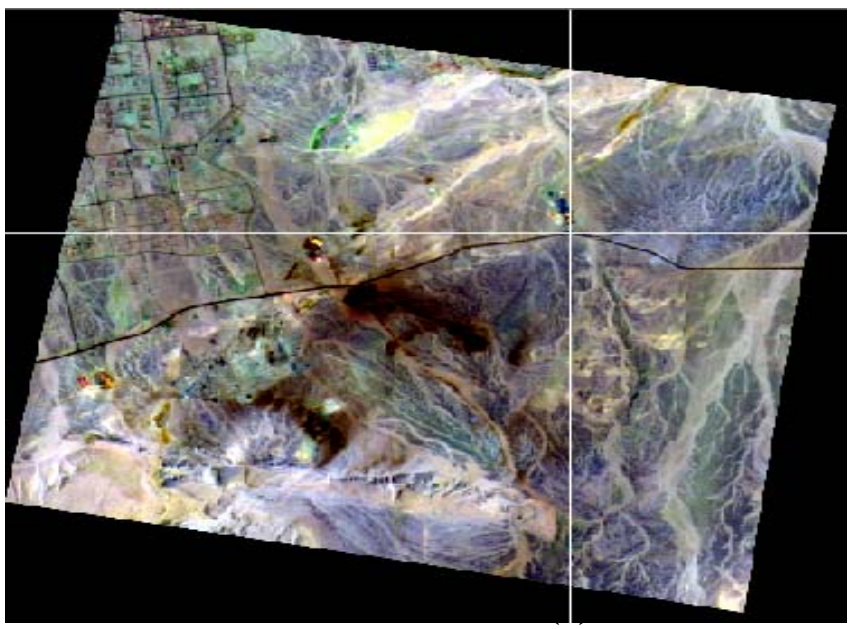

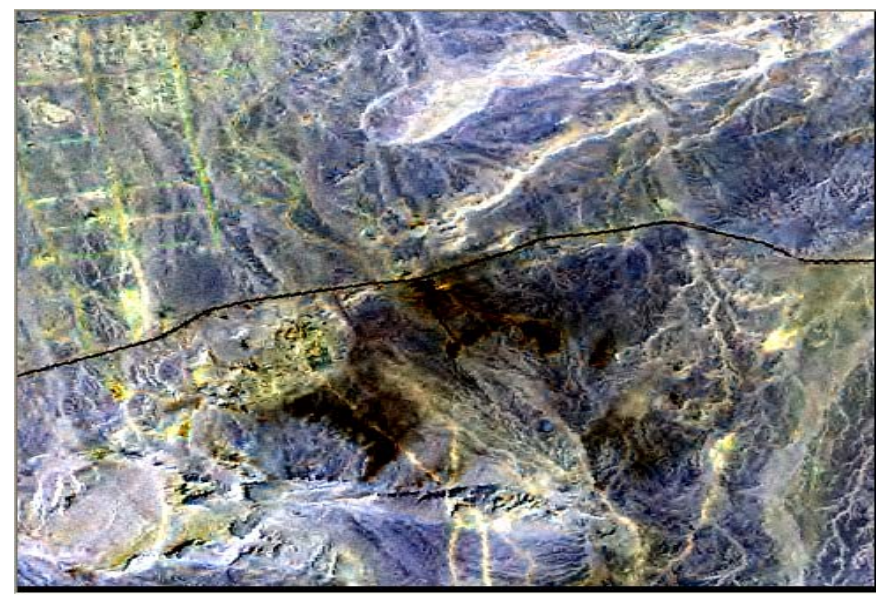

(b)

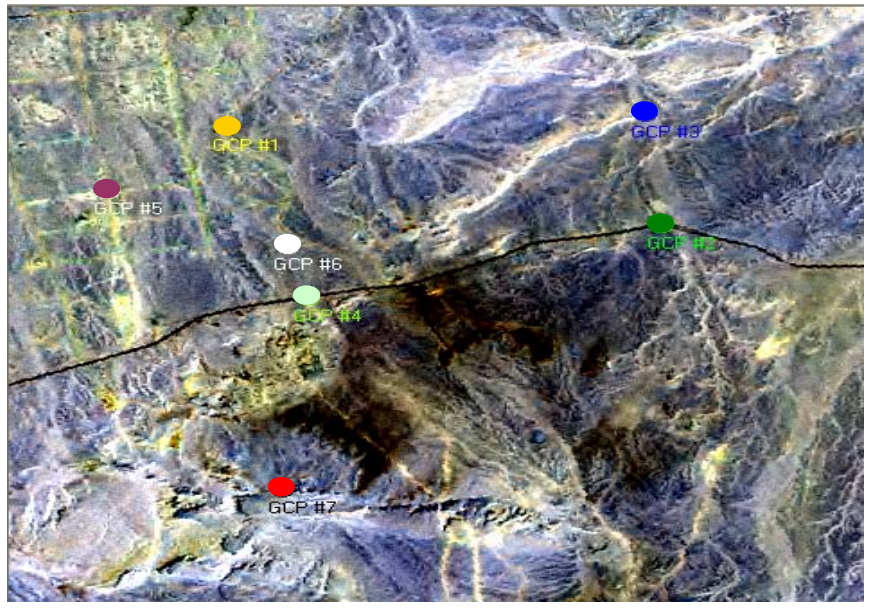

(d)

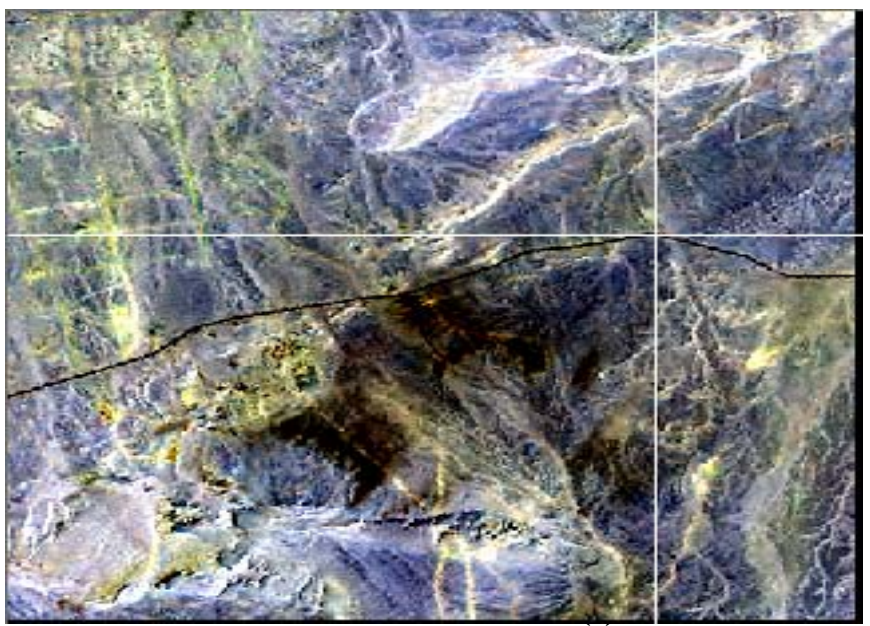

Fig. (2) a \& b - Raw image1 and its corresponding reference image, c \& d - 7 GCPs distribution on raw image1 and its reference, 


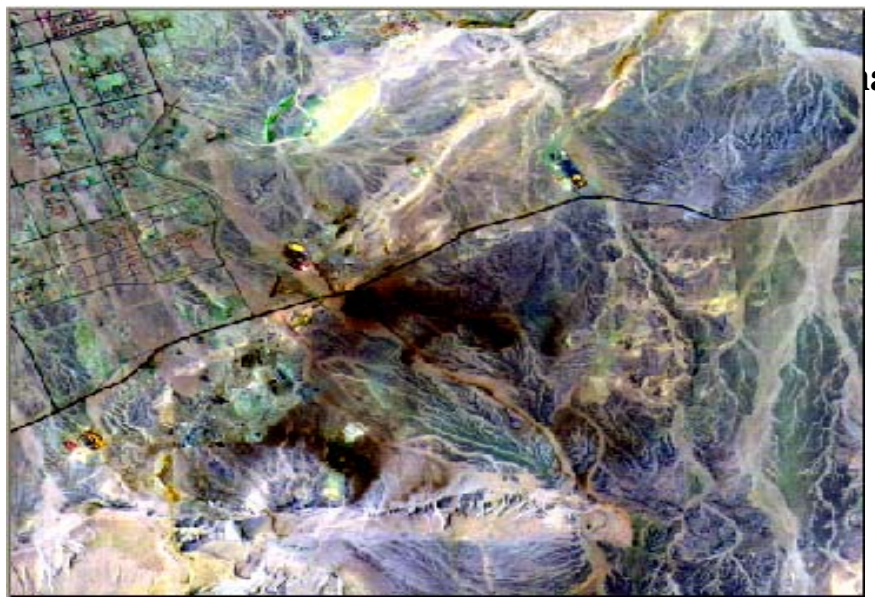

(a)

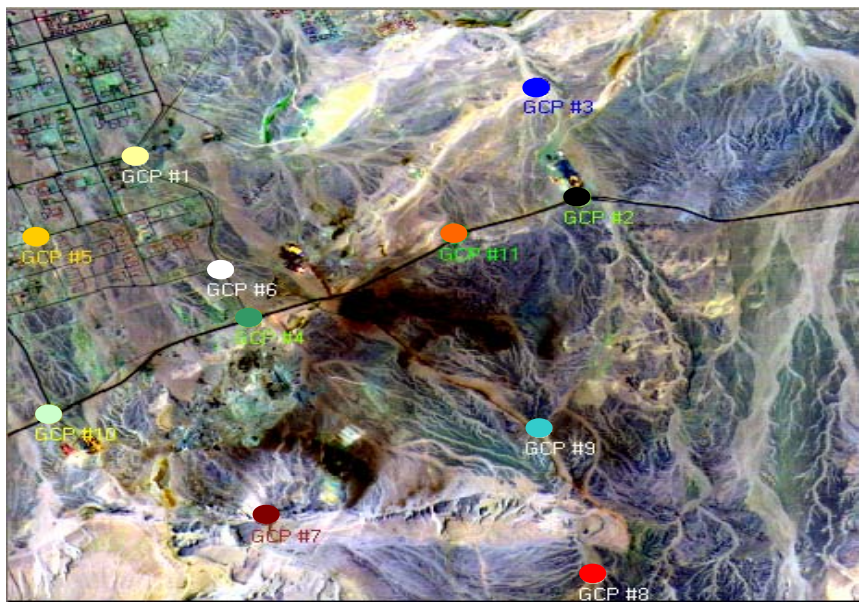

(c)

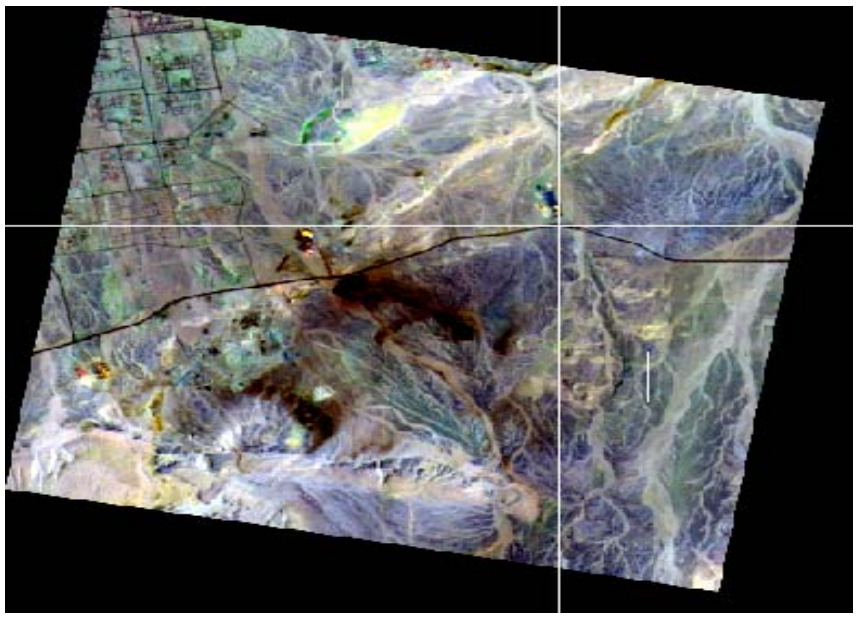

(e)

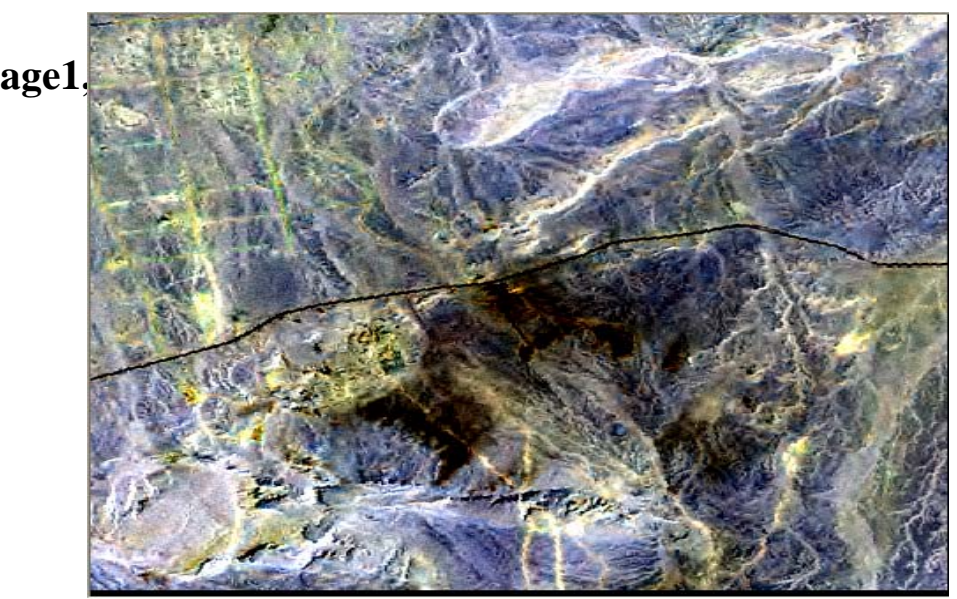

(b)

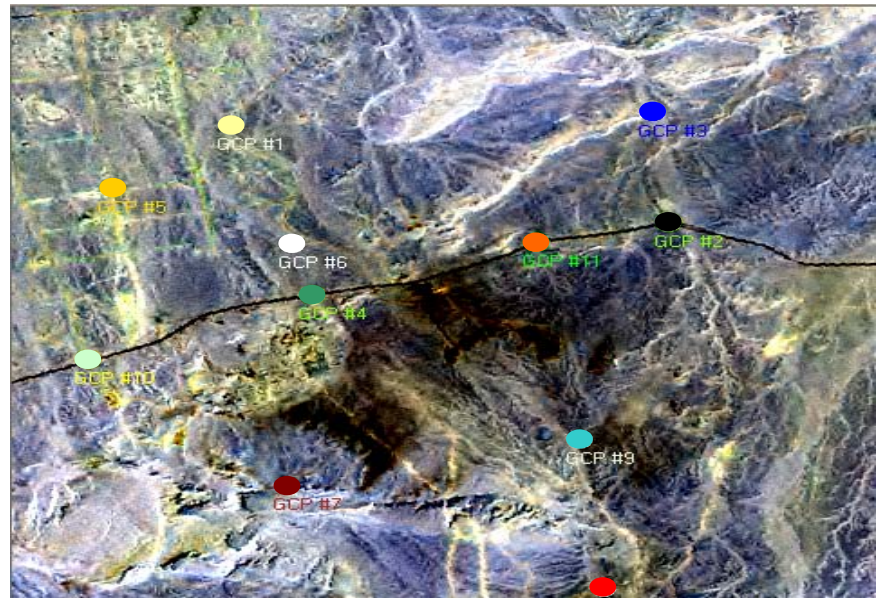

(d)

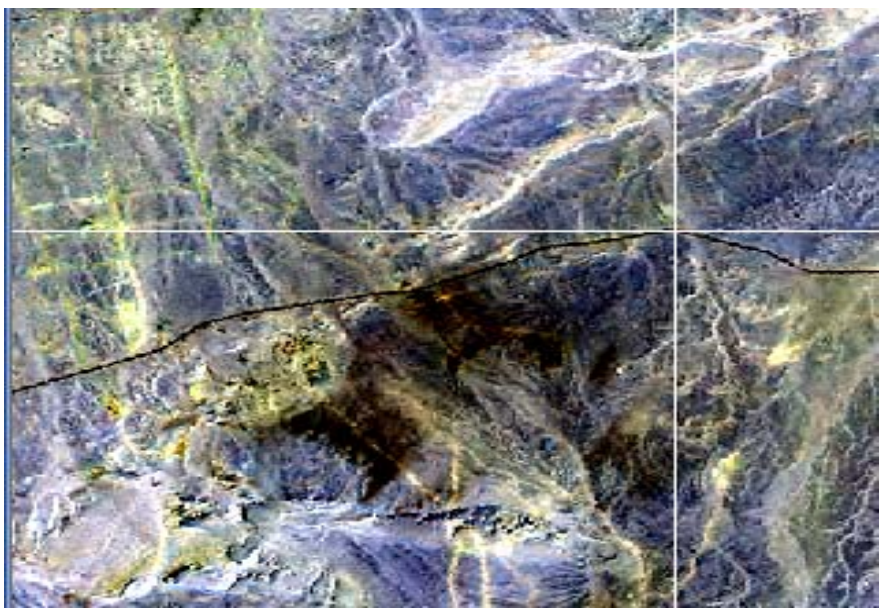

(f)

Fig. (3) a \& b - Raw image1 and its corresponding reference image, c \& d - 11 GCPs distribution on raw image1 and its reference, e \& f - Corrected image1, and its reference with link between them. 
Proceedings of the $5^{\text {th }}$ ICEENG Conference, 16-18 May, 2006

RE - 4 -11

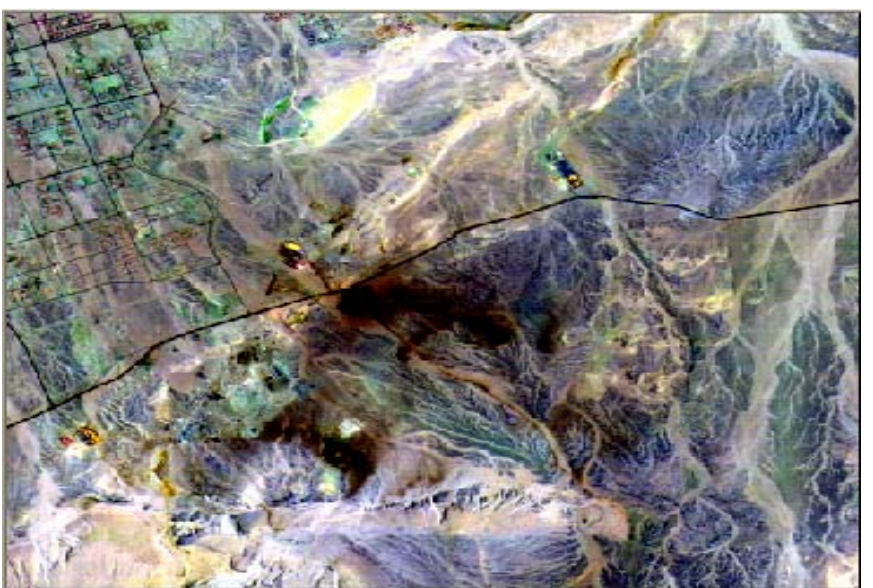

(a)

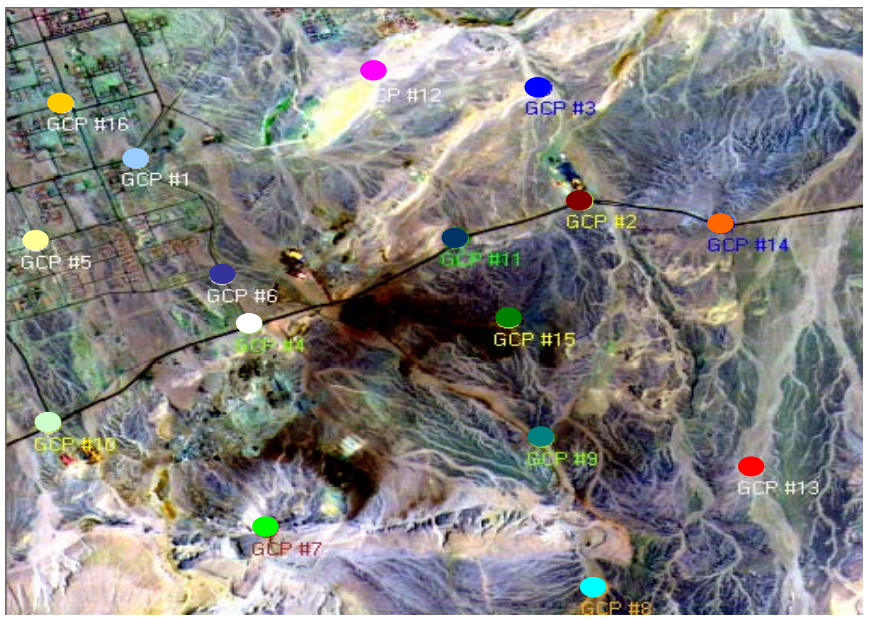

(c)

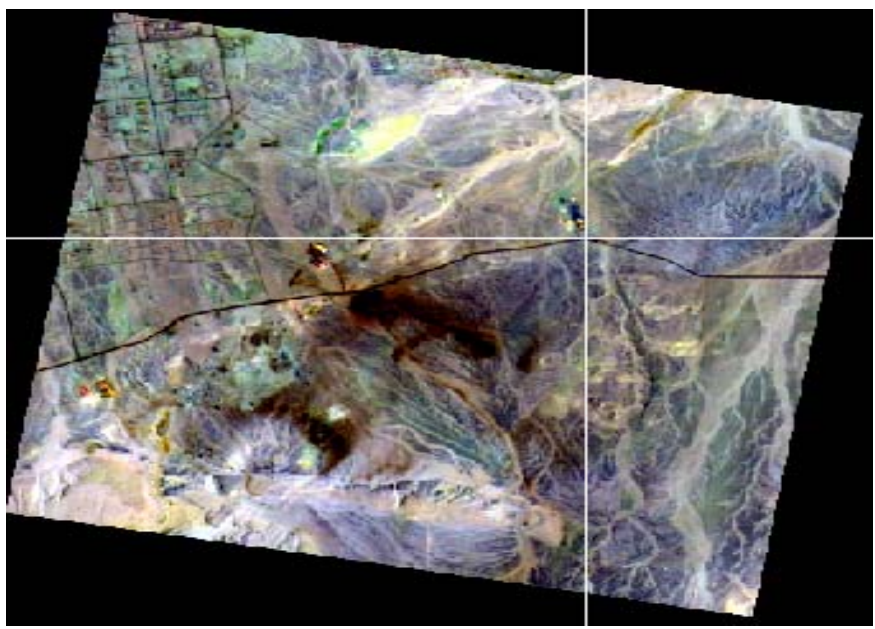

(e)

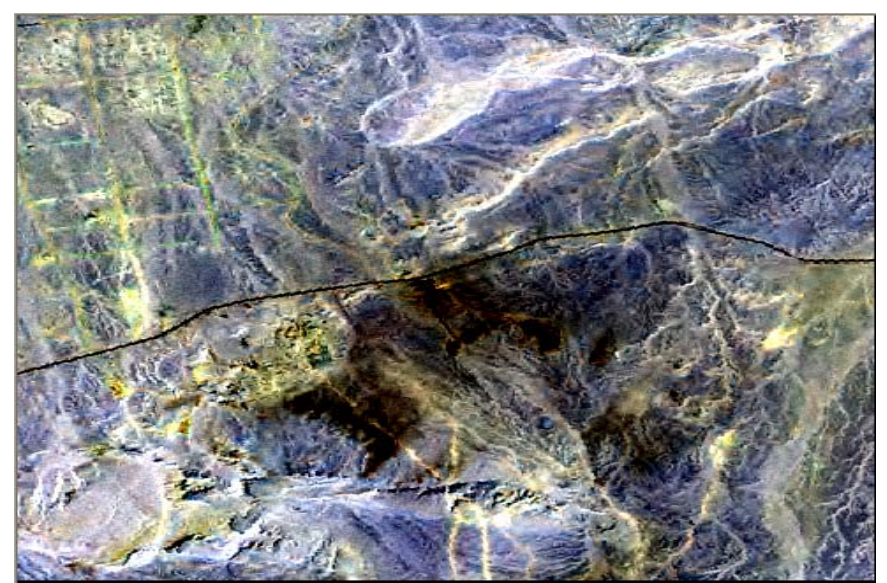

(b)

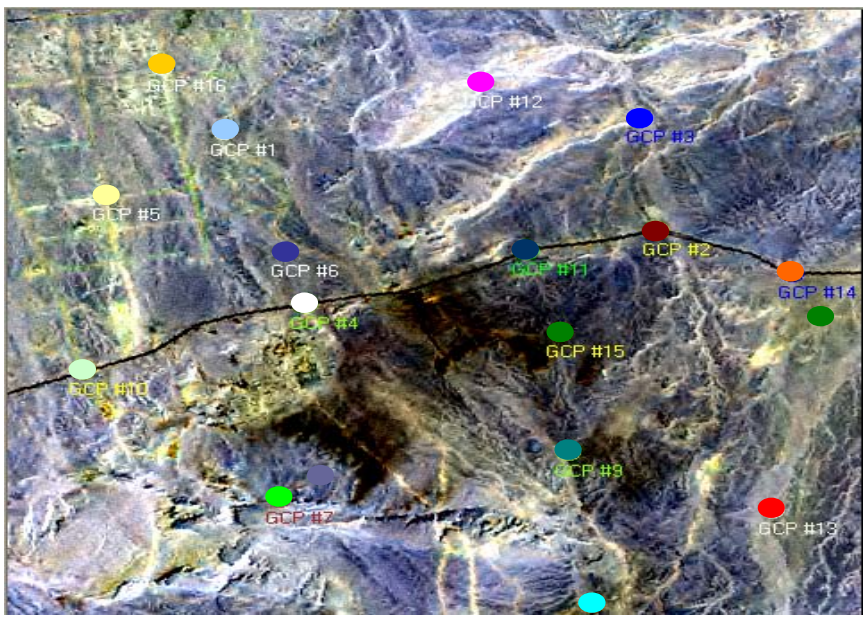

(d)

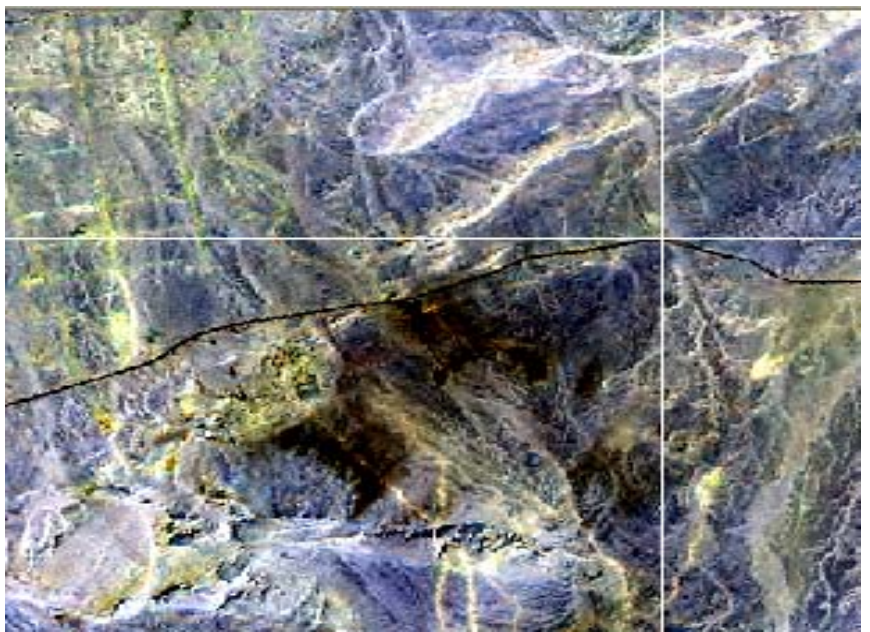

(f)

Fig. (4) a \& b - Raw image1 and its corresponding reference image, c \& d - 16 GCPs distribution on raw image1 and its reference, e \& f - Corrected image1, and its reference with link between them. 
Proceedings of the $5^{\text {th }}$ ICEENG Conference, 16-18 May, 2006

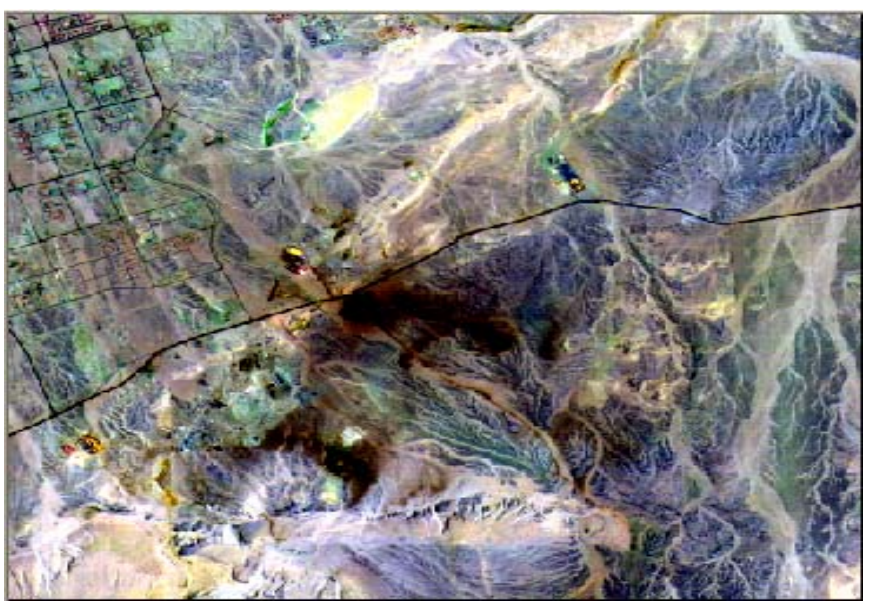

(a)

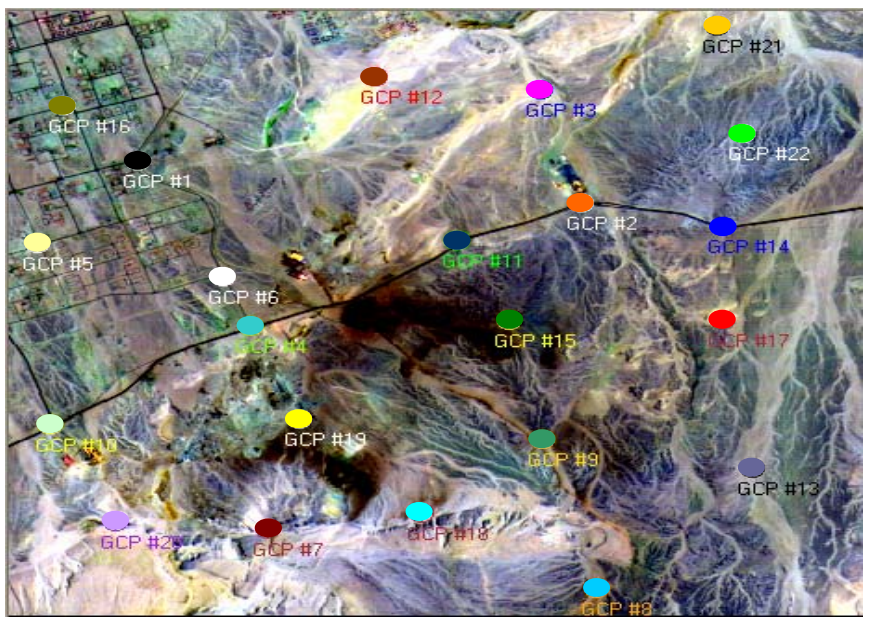

(c)

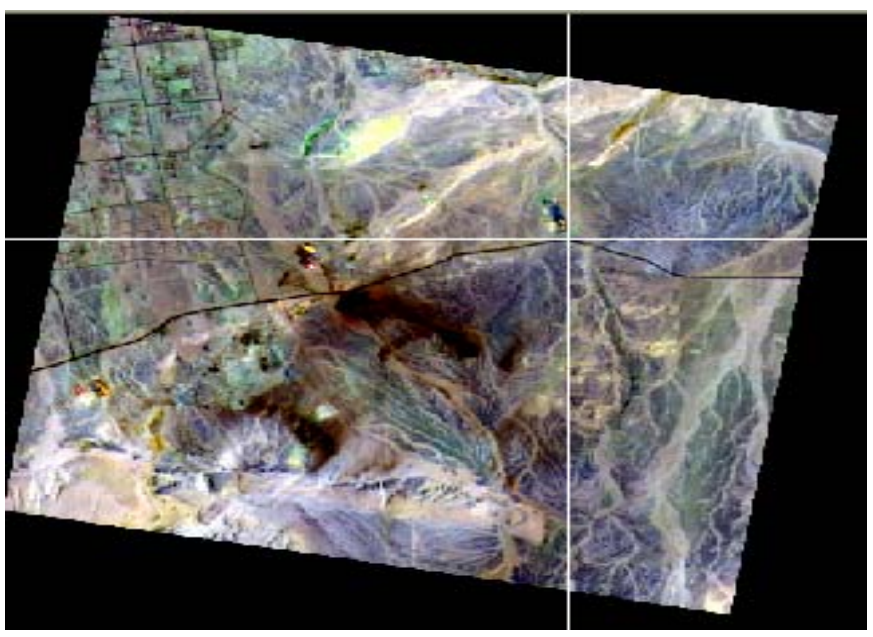

(e)

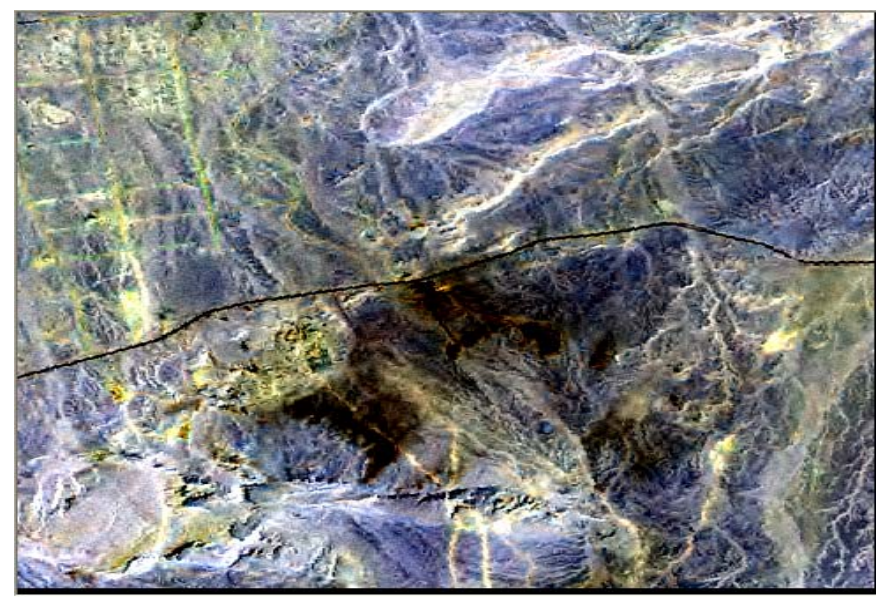

(b)

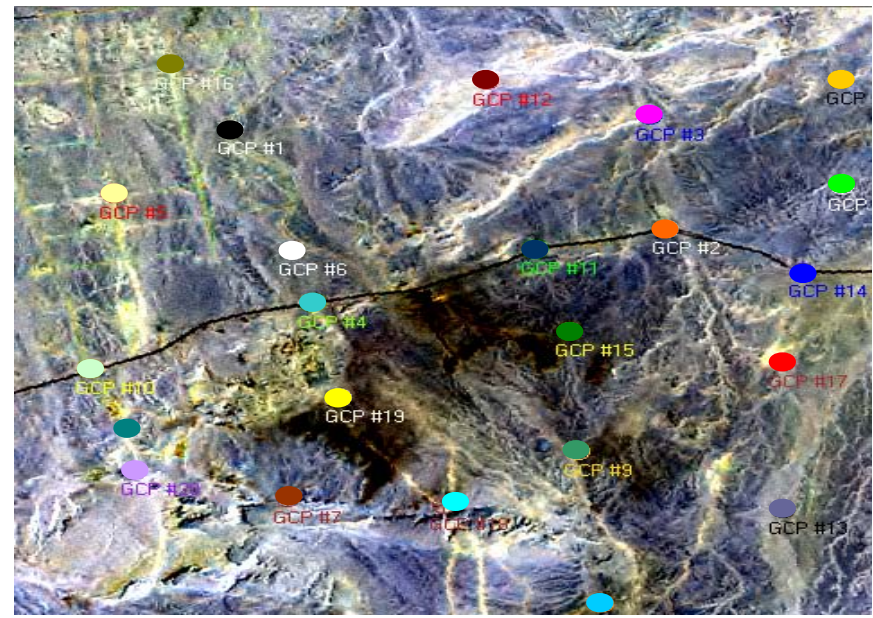

(d)

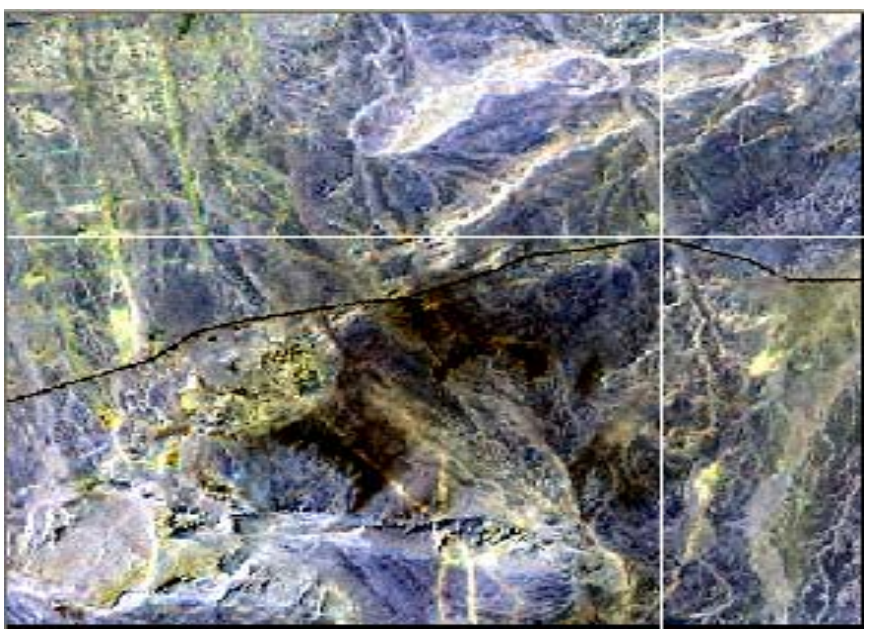

(f)

Fig. (5) a \& b - Raw image1 and its corresponding reference image, c \& d - 22 GCPs distribution on raw image1 and its reference, e \& f - Corrected image1, and its reference with link between them. 


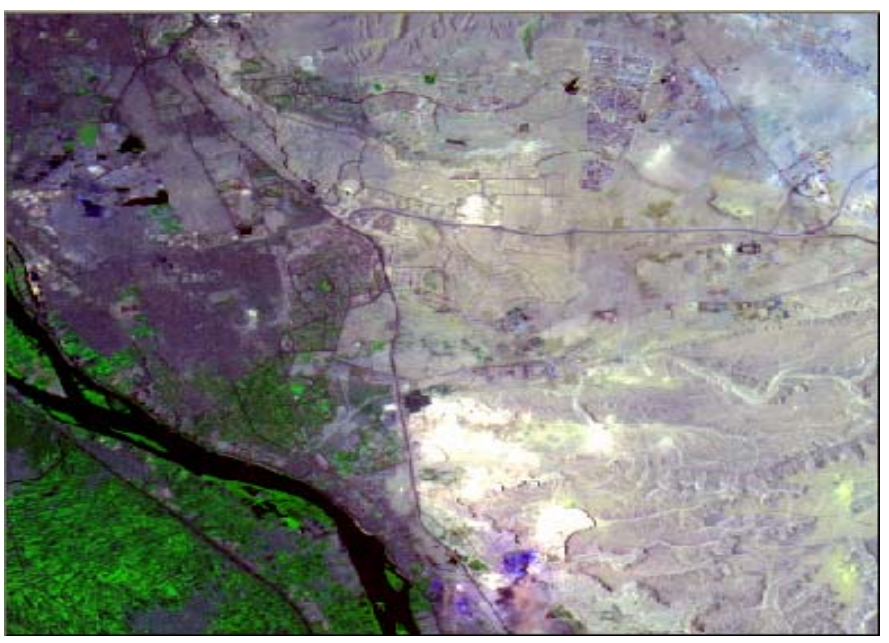

(a)

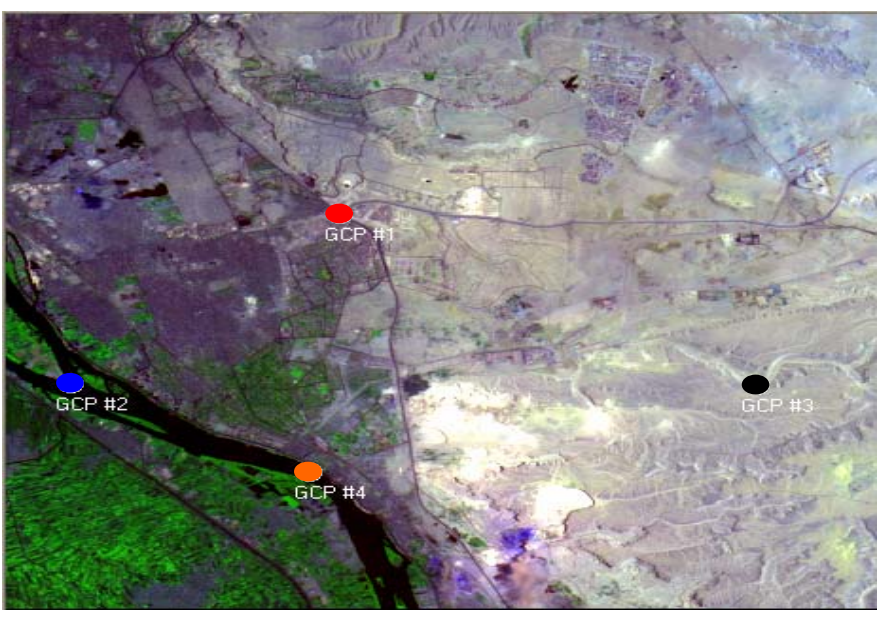

(c)

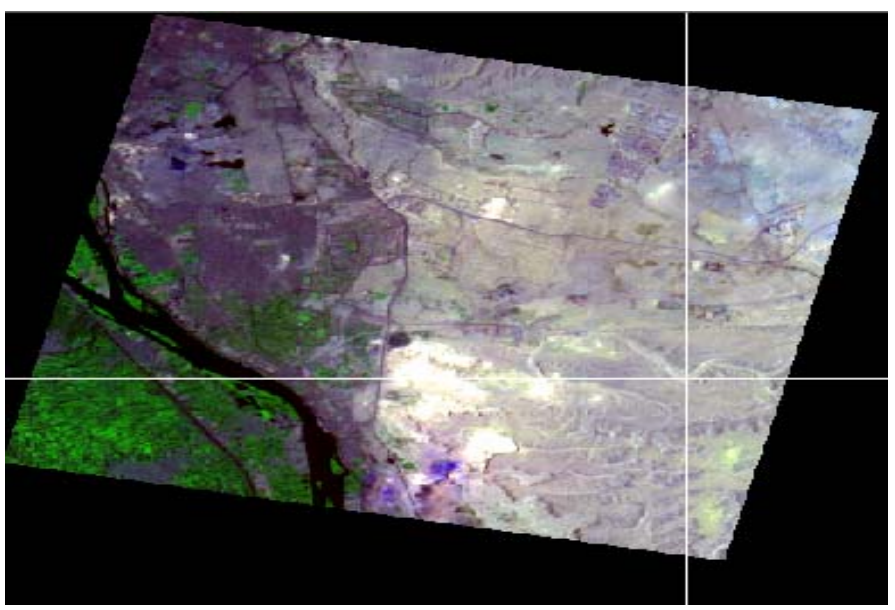

(e)

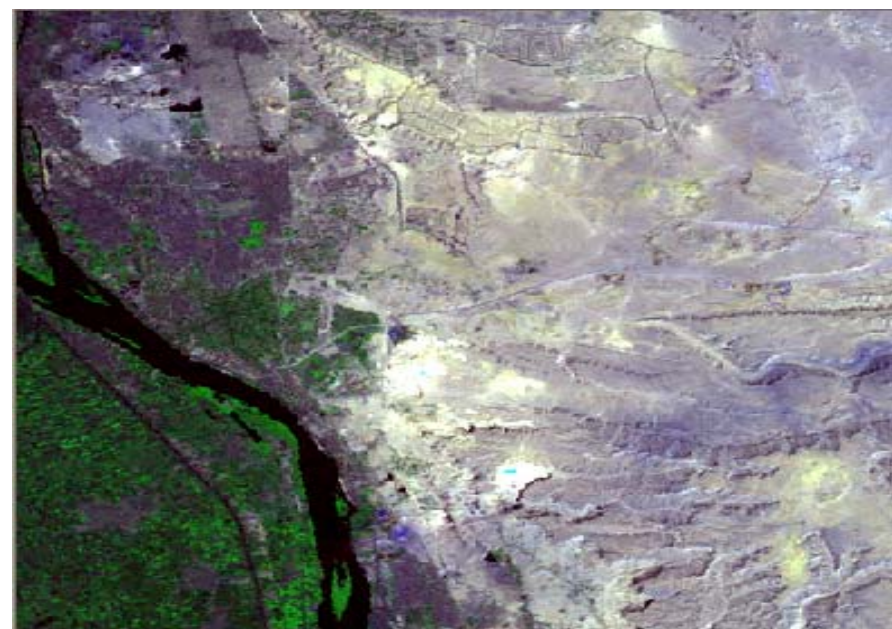

(b)

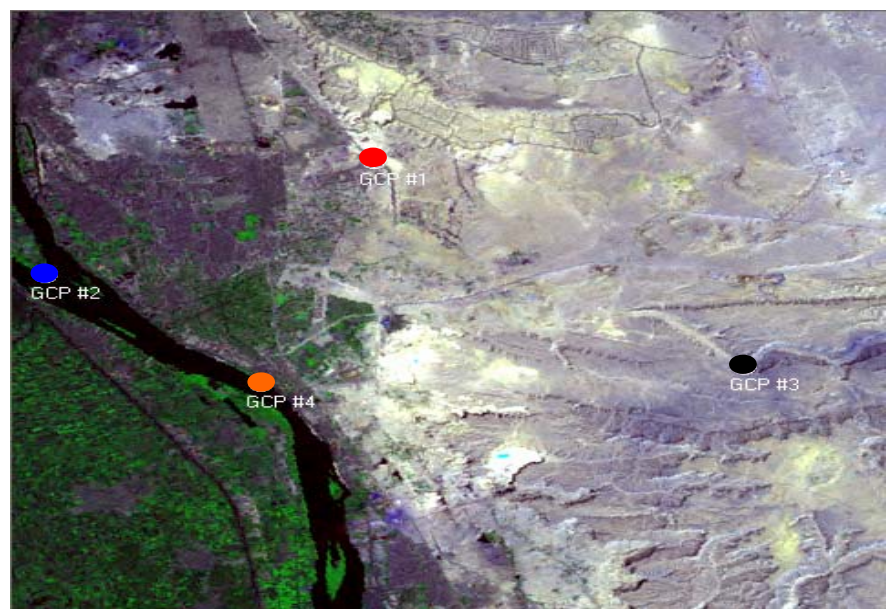

(d)

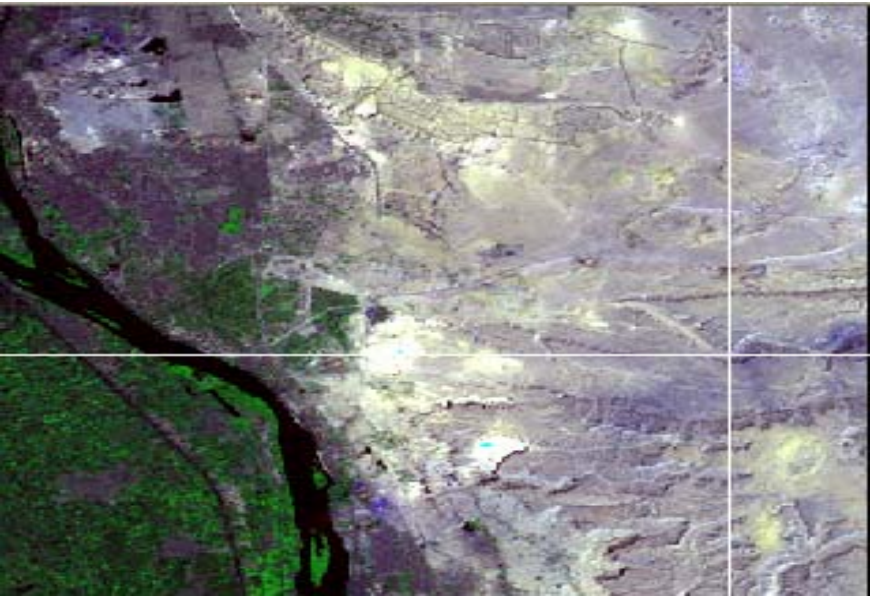

(f)

Fig. (6) a \& b - Raw image2 and its corresponding reference image, c \& d - 4 GCPs distribution on raw image 2 and its reference, e \& f - Corrected image2, and its reference with link between them. 


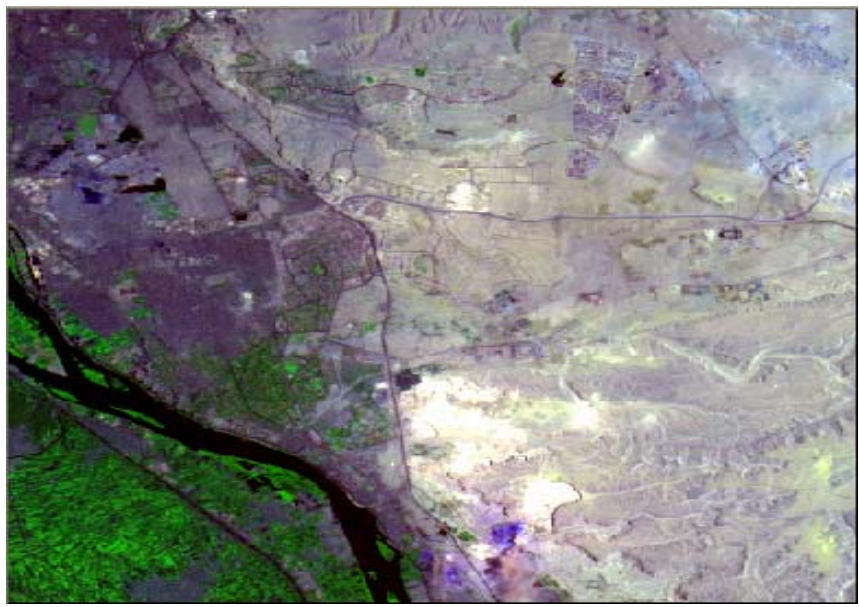

(a)

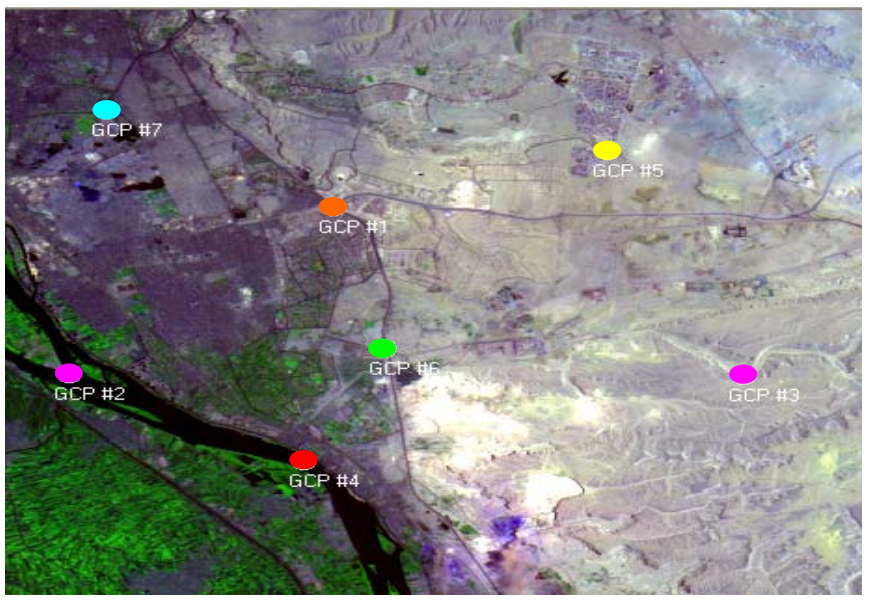

(c)

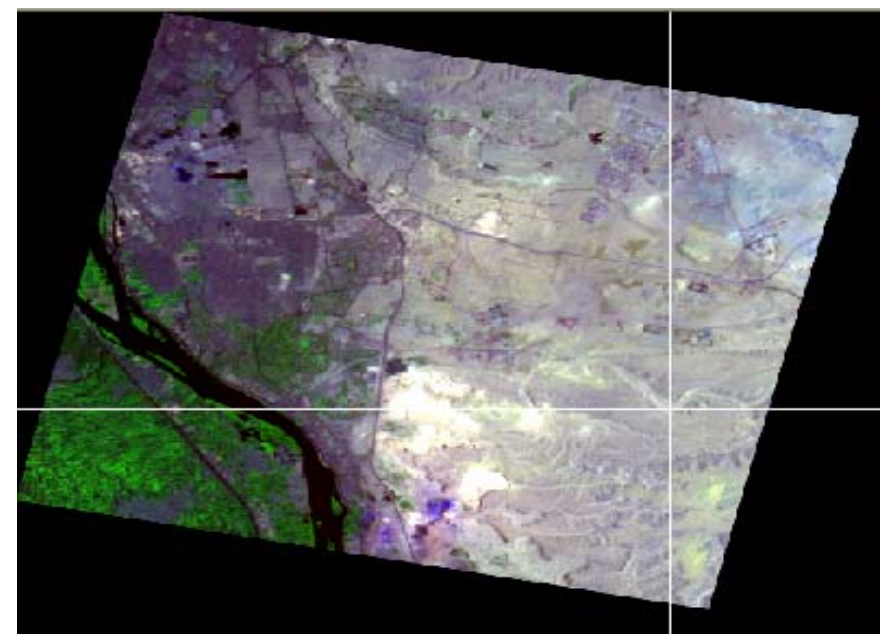

(e)

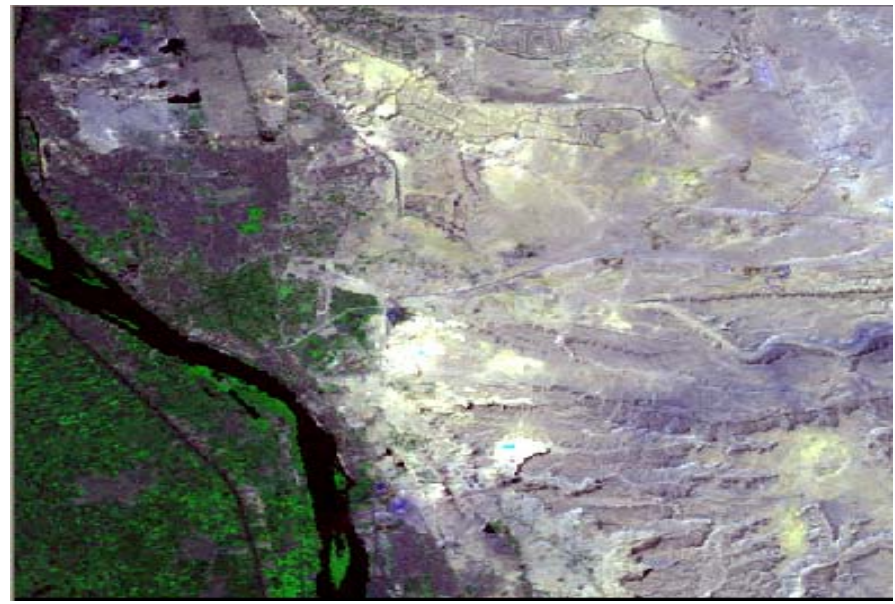

(b)

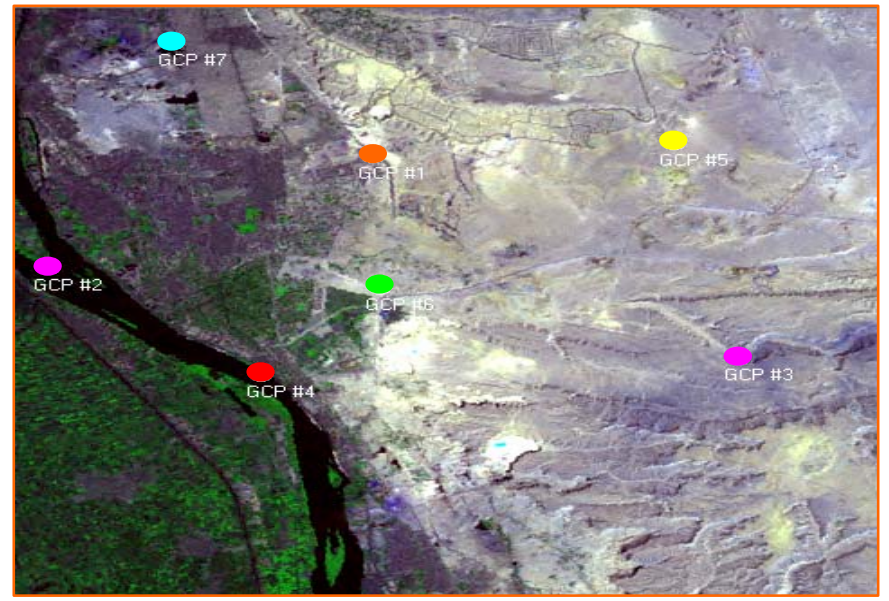

(d)

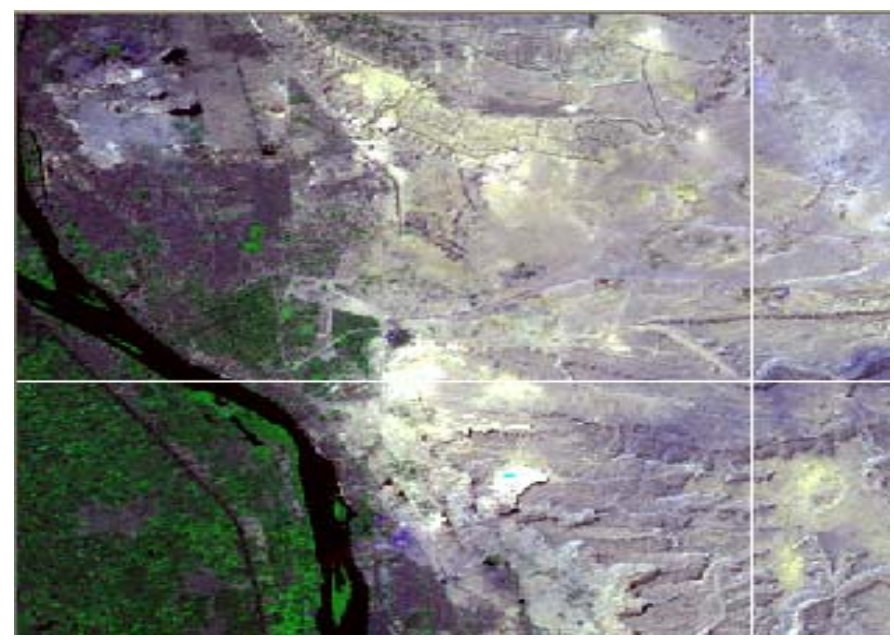

(f)

Fig. (7) a \& b - Raw image2 and its corresponding reference image, c \& d - 7 GCPs distribution on raw image2 and its reference, e \& f - Corrected image2, and its reference with link between them. 


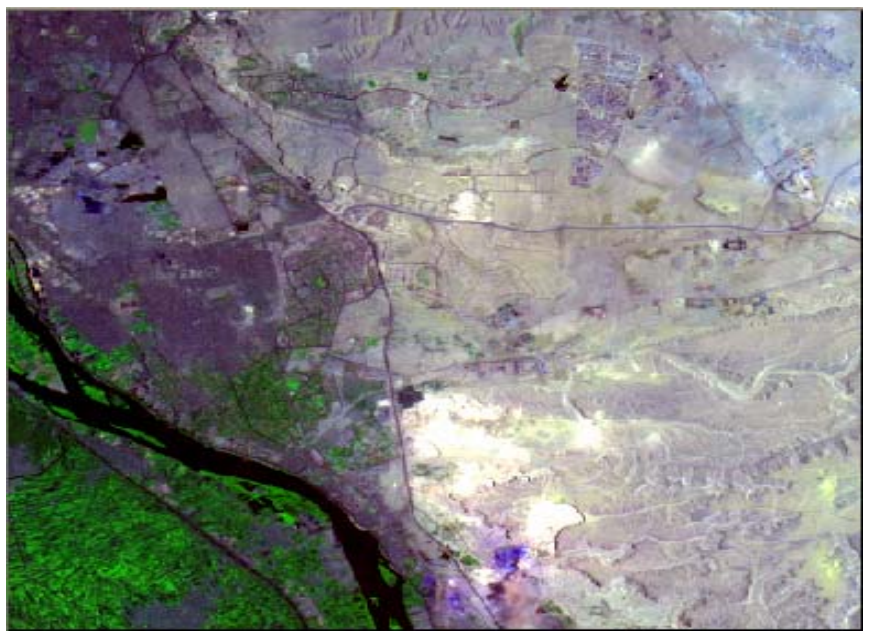

(a)

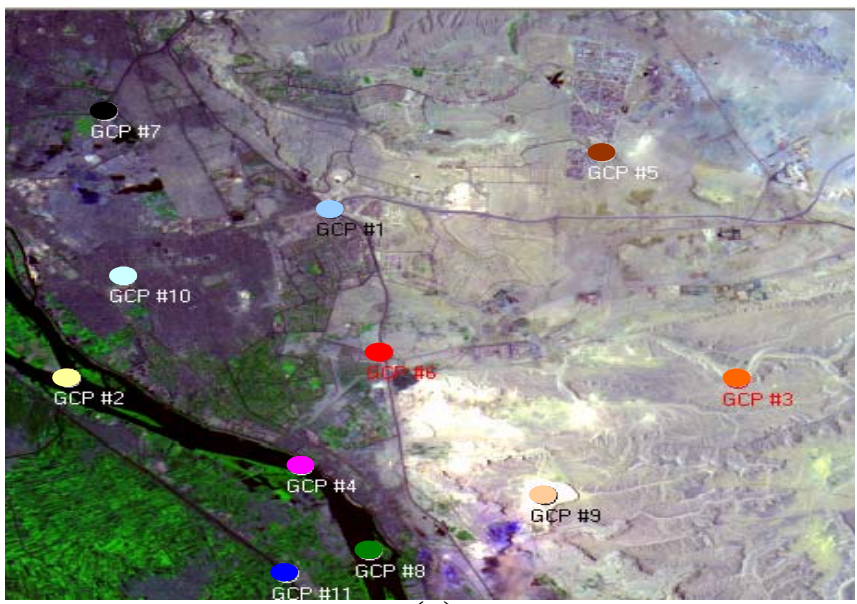

(c)

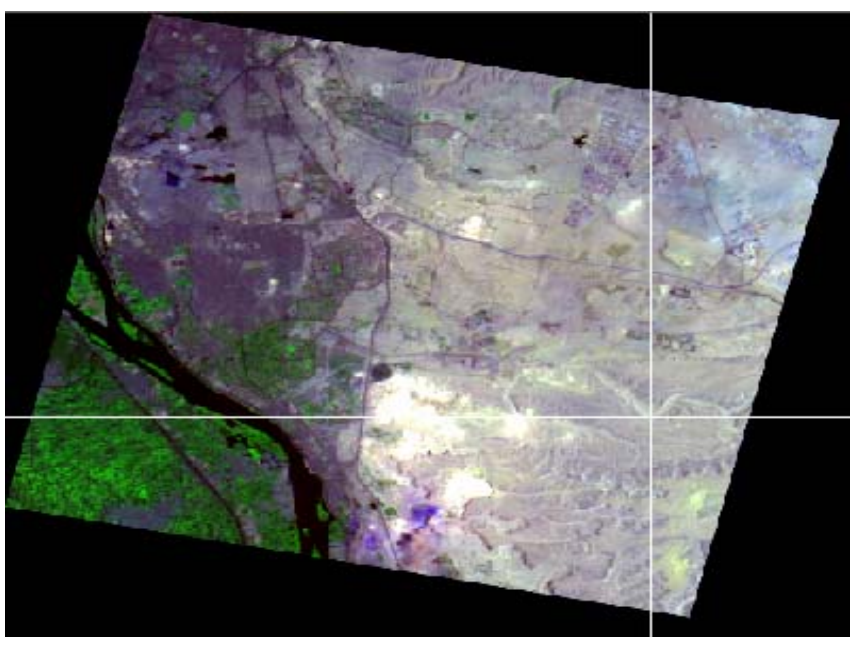

(e)

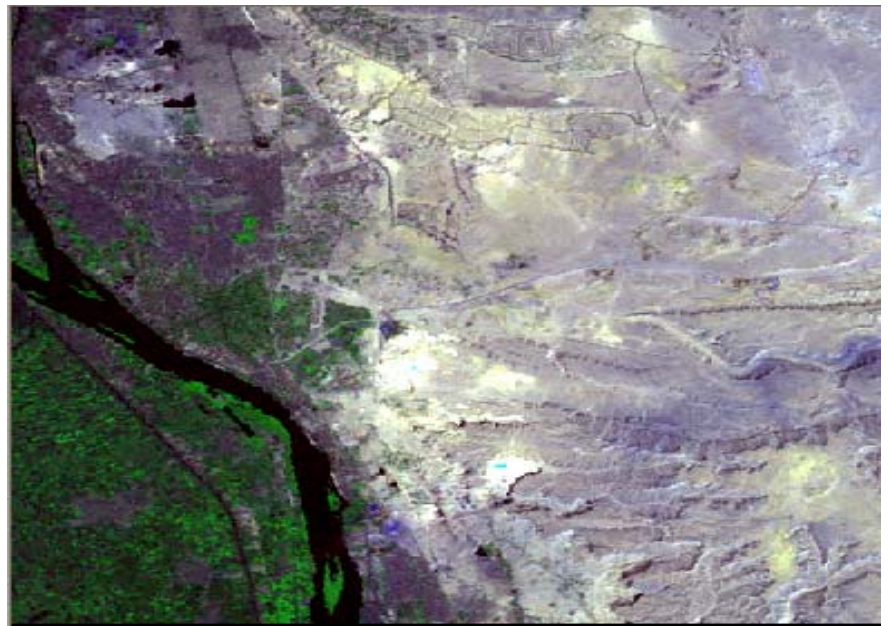

(b)

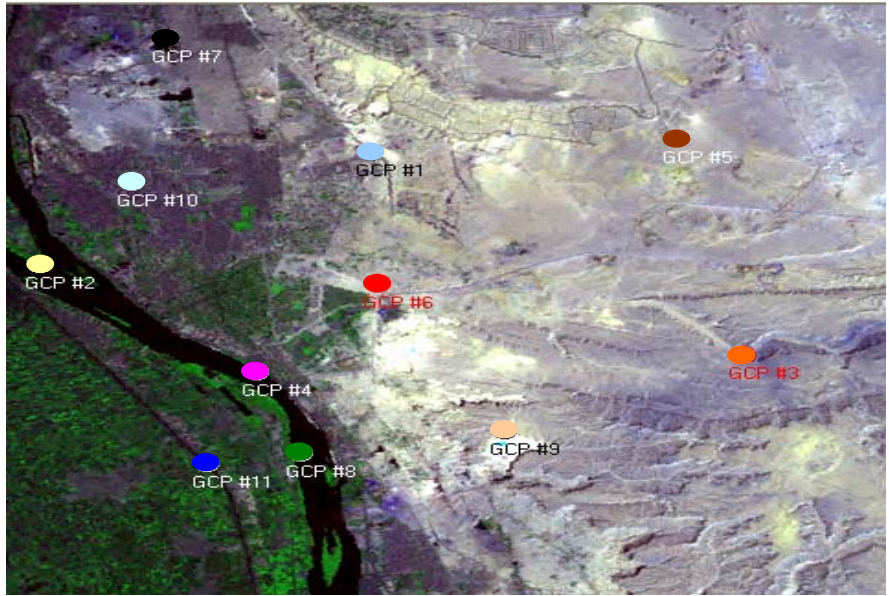

(d)

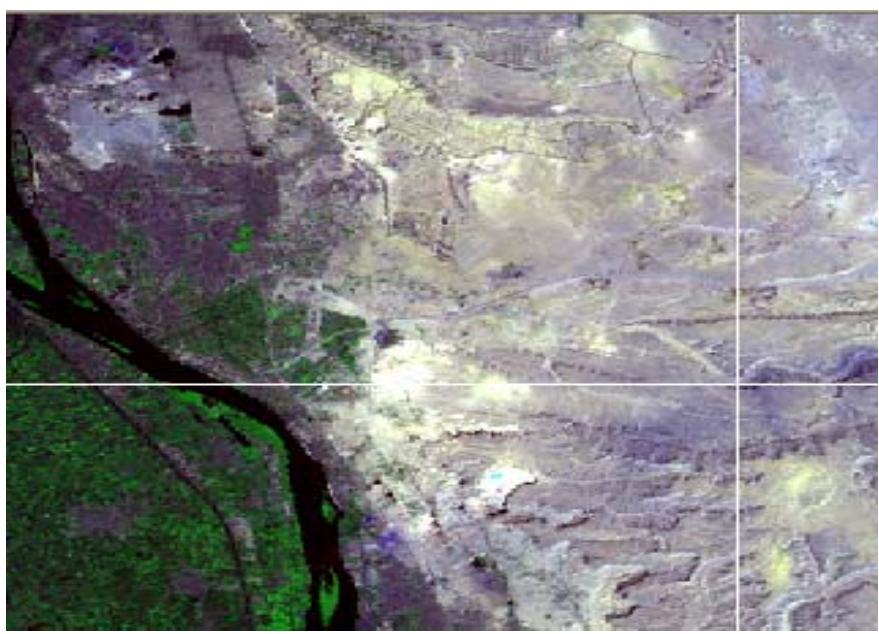

(f)

Fig. (8) a \& b - Raw image2 and its corresponding reference image, c \& d - 11 GCPs distribution on raw image2 and its reference, e \& f - Corrected image2, and its reference with link between them. 


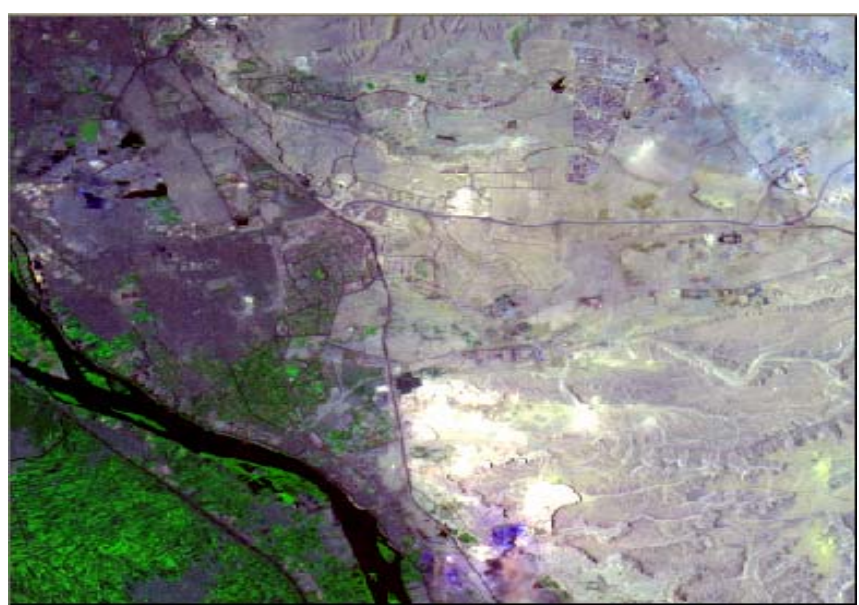

(a)

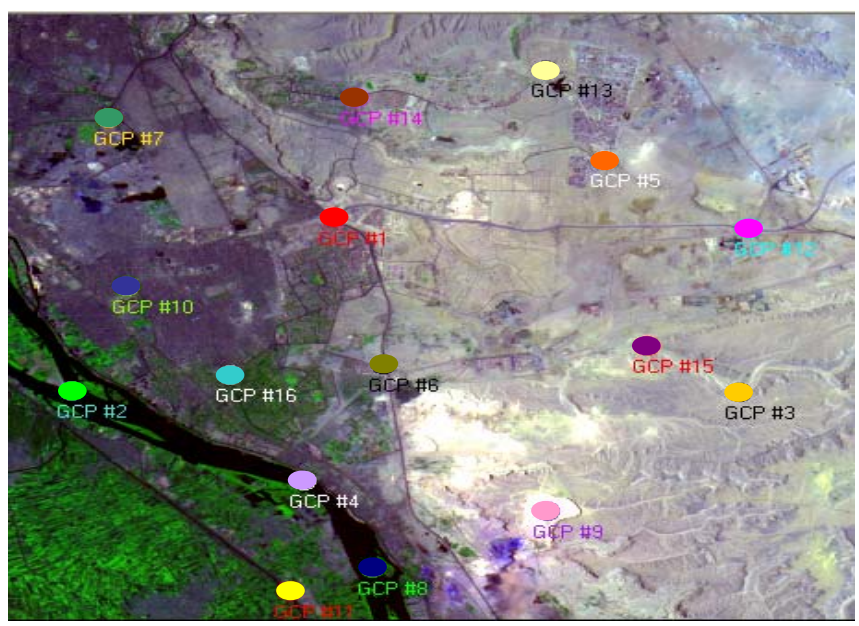

(c)

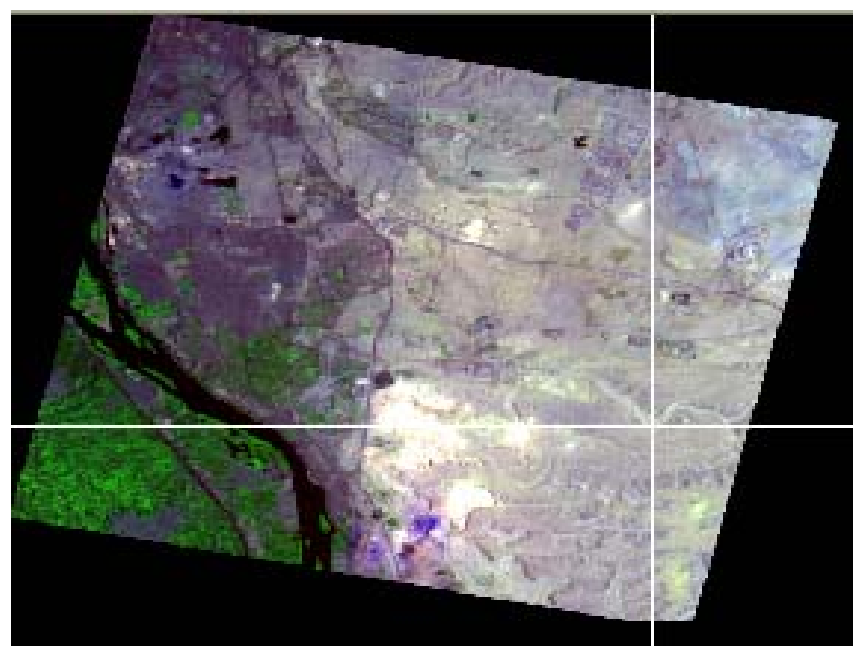

(e)

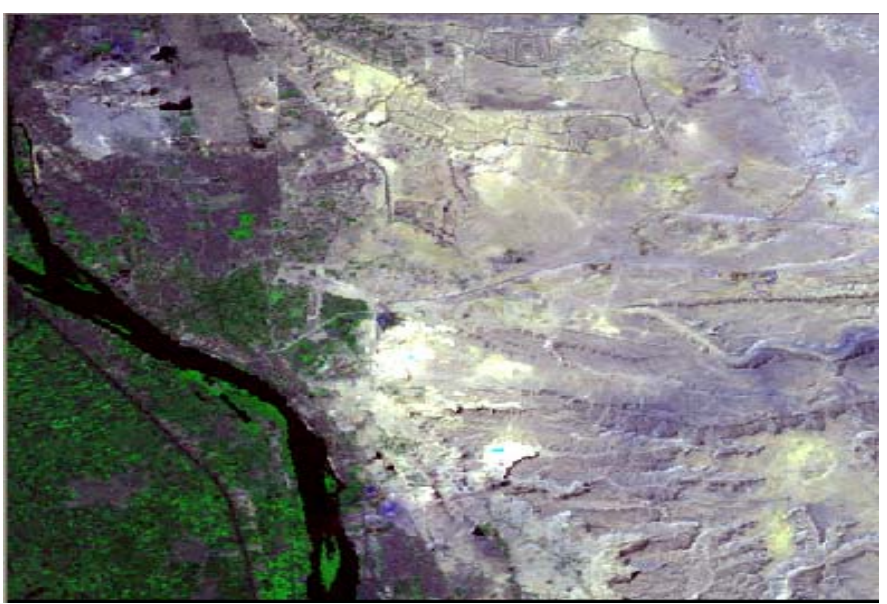

(b)

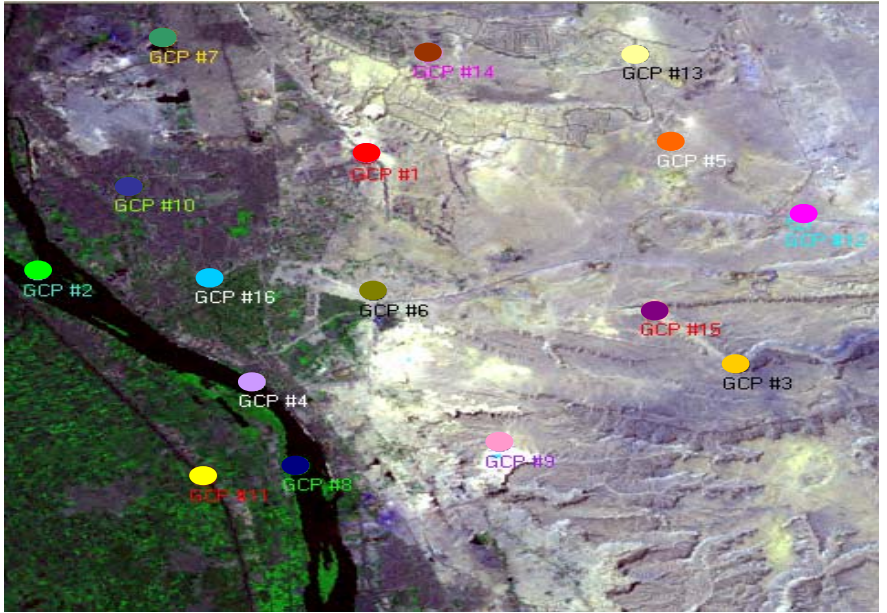

(d)

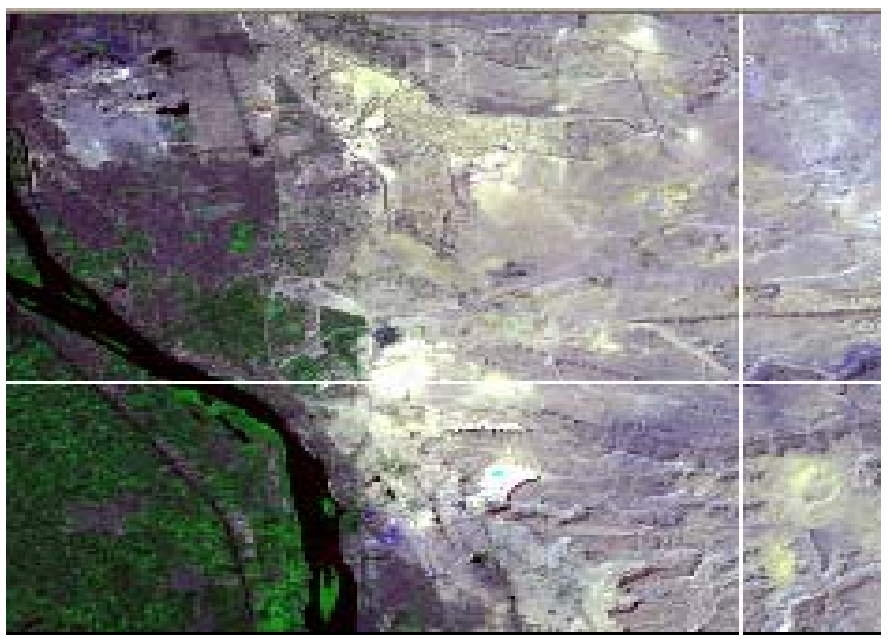

(f)

Fig. (9) a \& b - Raw image2 and its corresponding reference image, c \& d - 16 GCPs distribution on raw image2 and its reference, e \& f - Corrected image2, and its reference with link between them. 


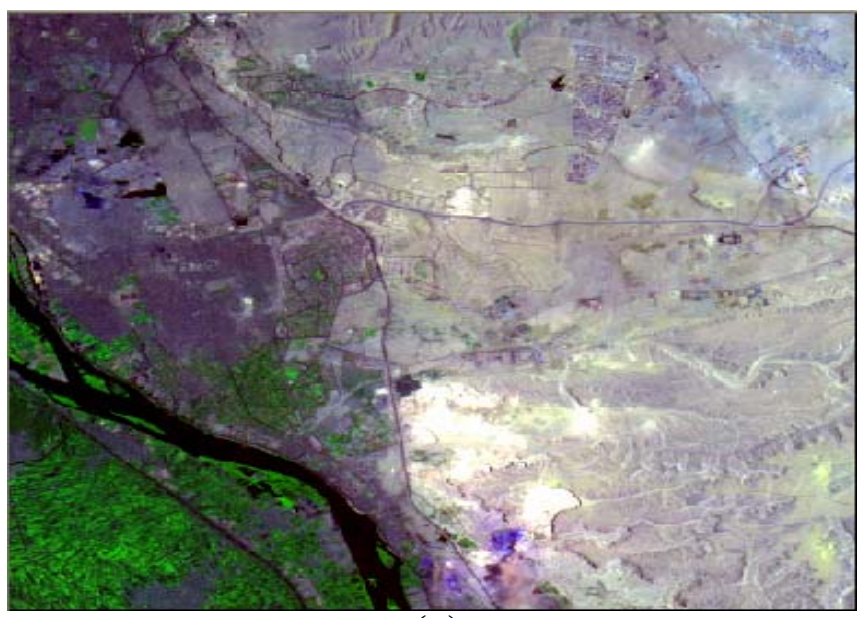

(a)

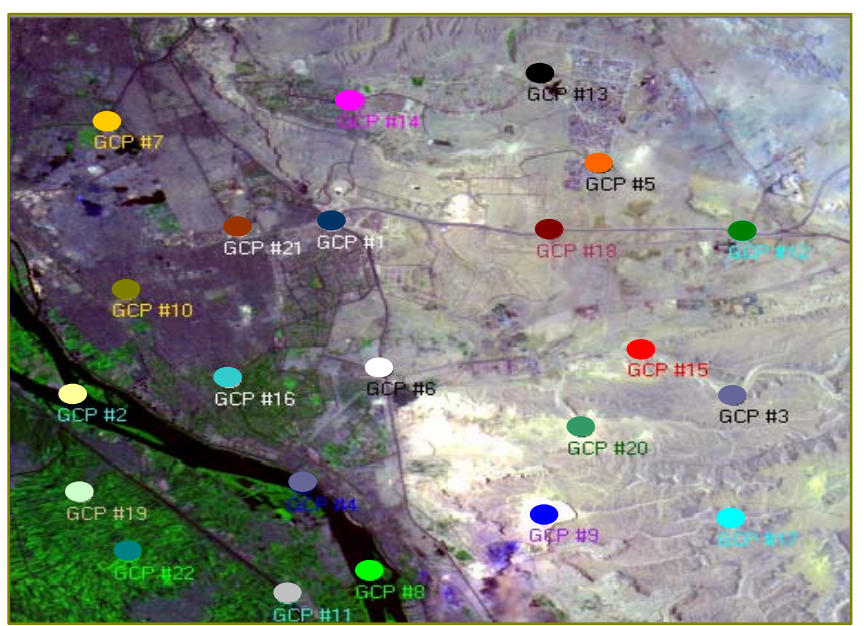

(c)

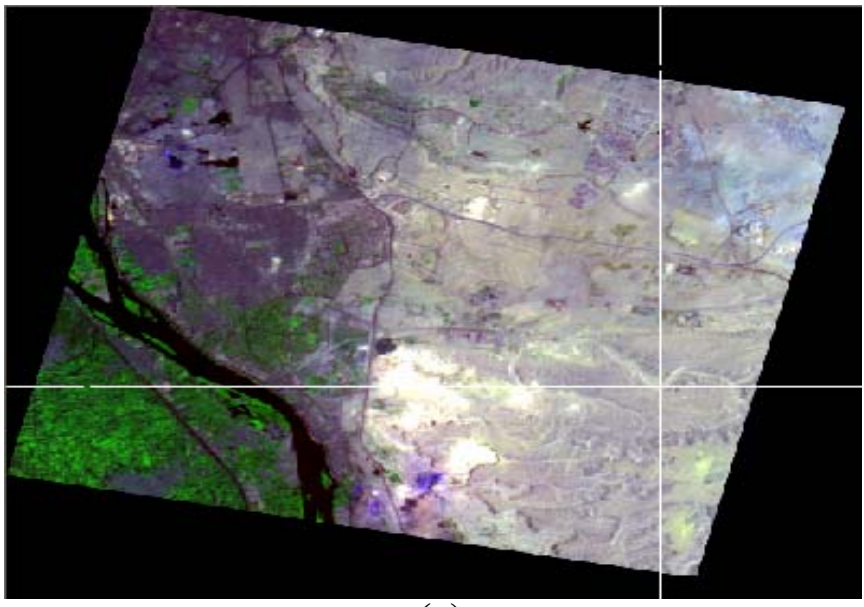

(e)

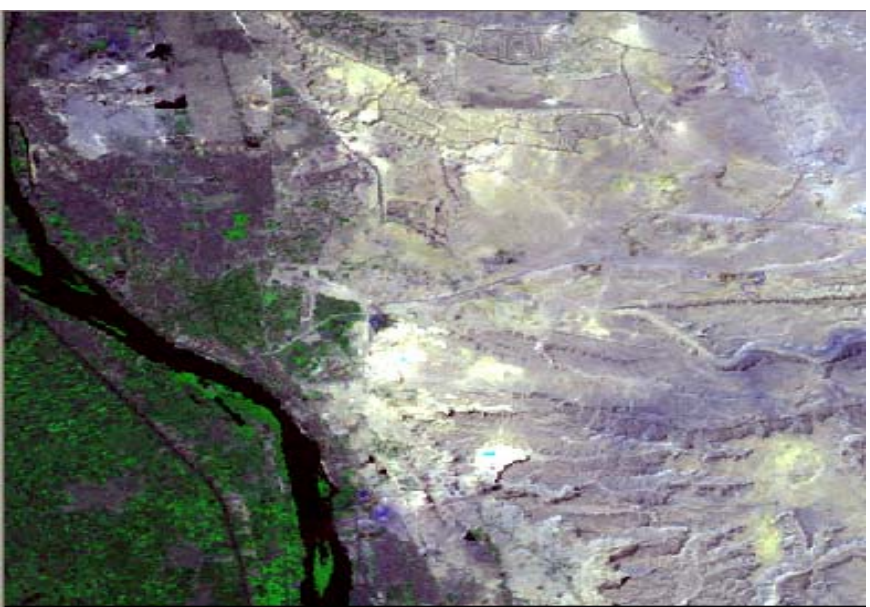

(b)

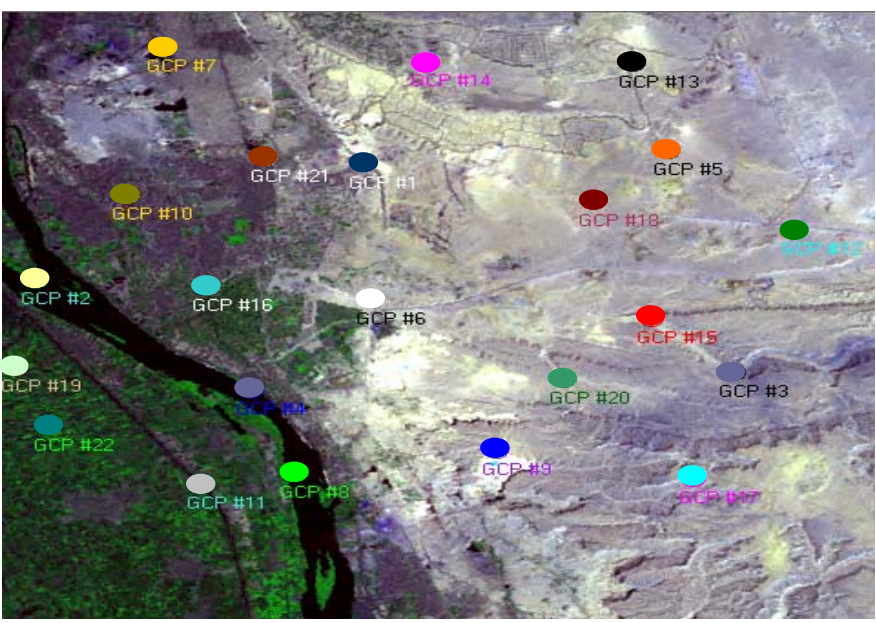

(d)

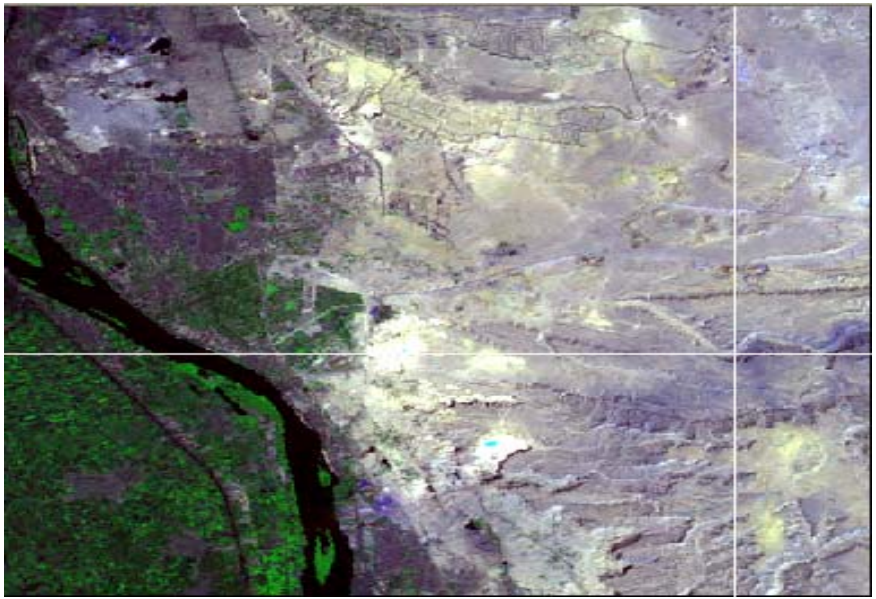

(f)

Fig. (10) a \& b - Raw image2 and its corresponding reference image, c \& d - 22 GCPs distribution on raw image2 and its reference, e \& f - Corrected image2, and its reference with link between them. 


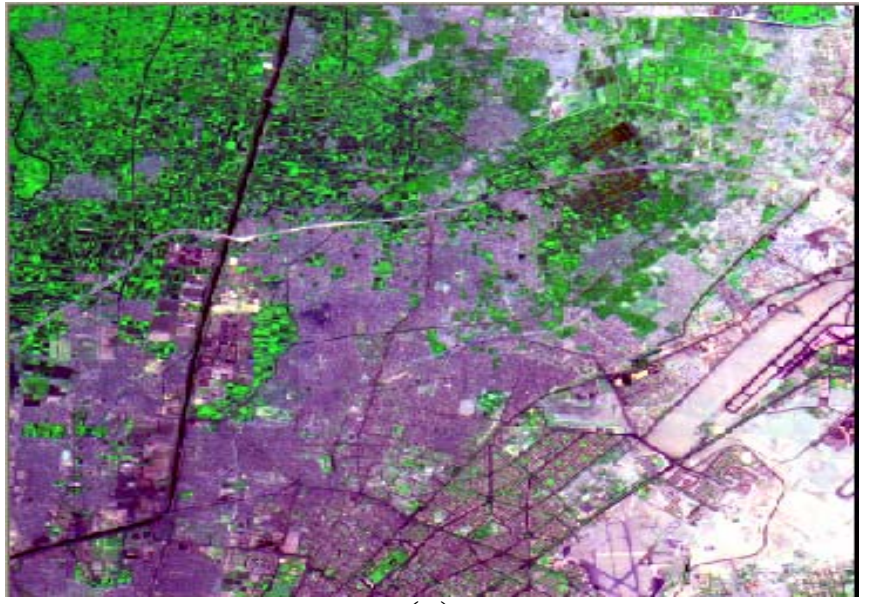

(a)

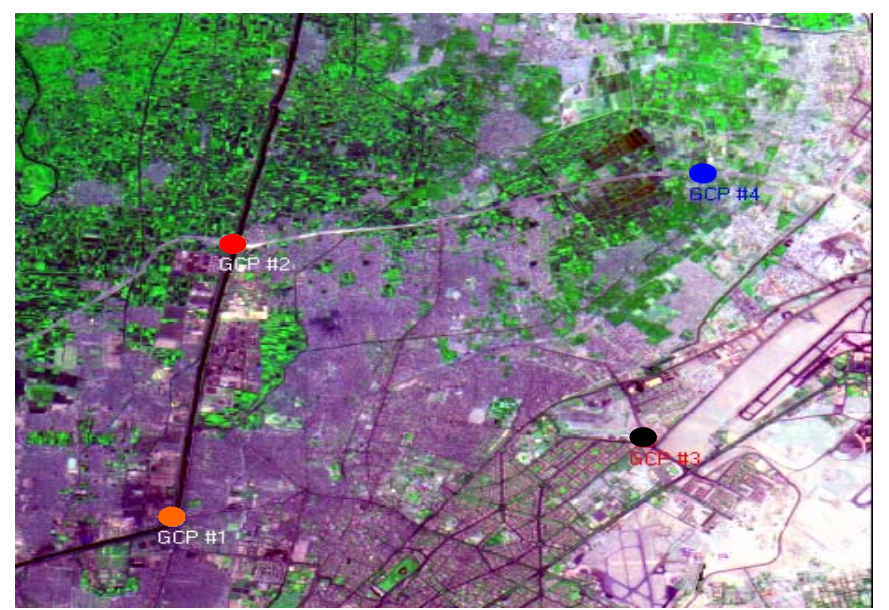

(c)

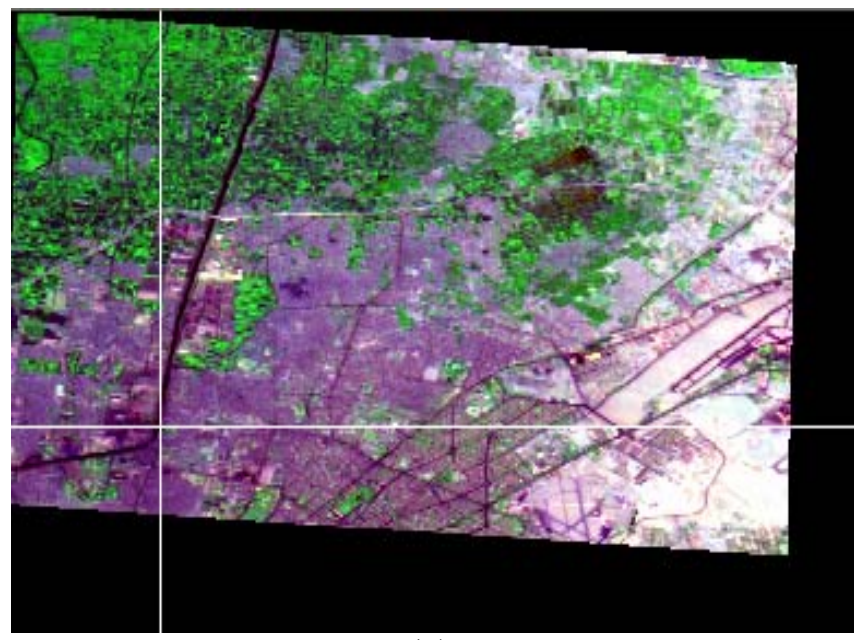

(e)

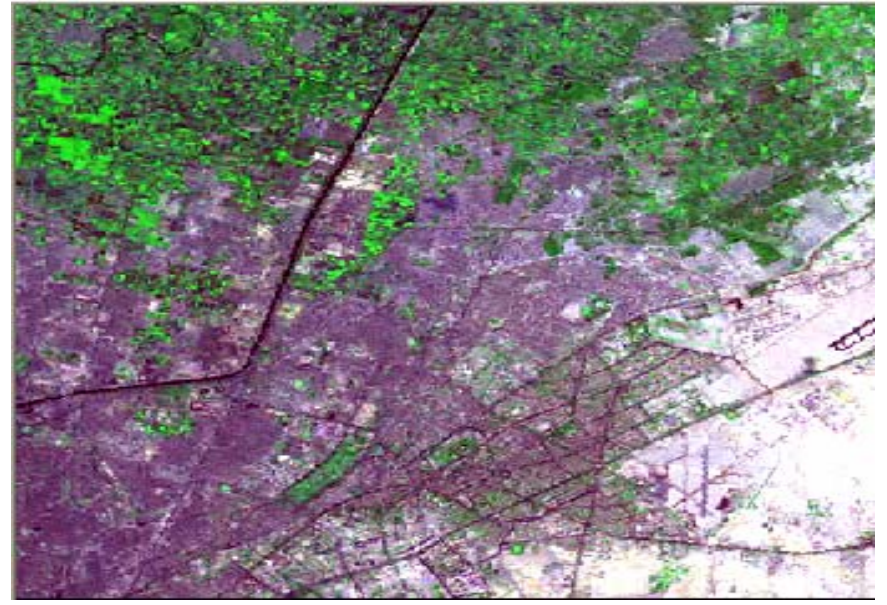

(b)

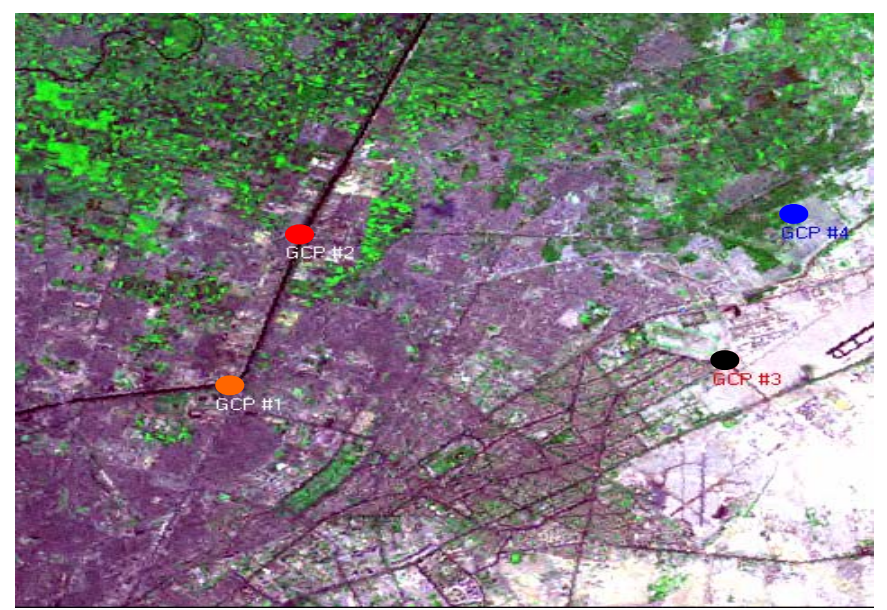

(d)

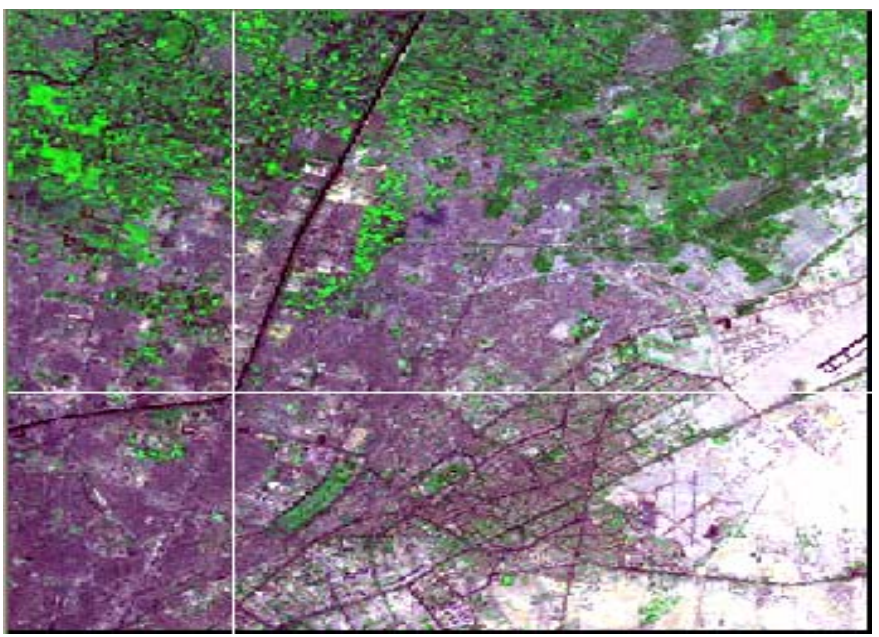

(f)

Fig. (11) a \& b - Raw image3 and its corresponding reference image, c \& d - 4 GCPs distribution on raw image3 and its reference, e \& f - Corrected image3, and its reference with link between them. 


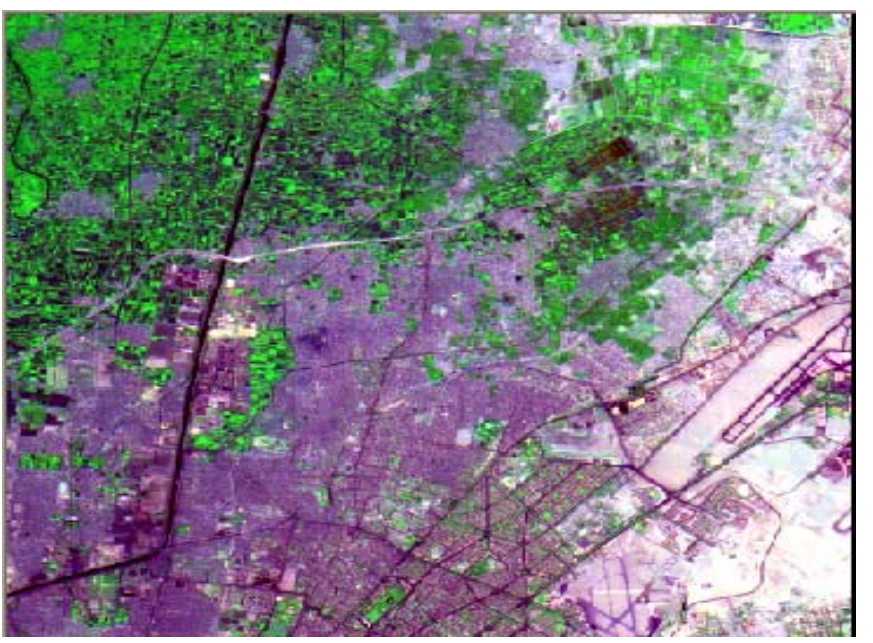

(a)

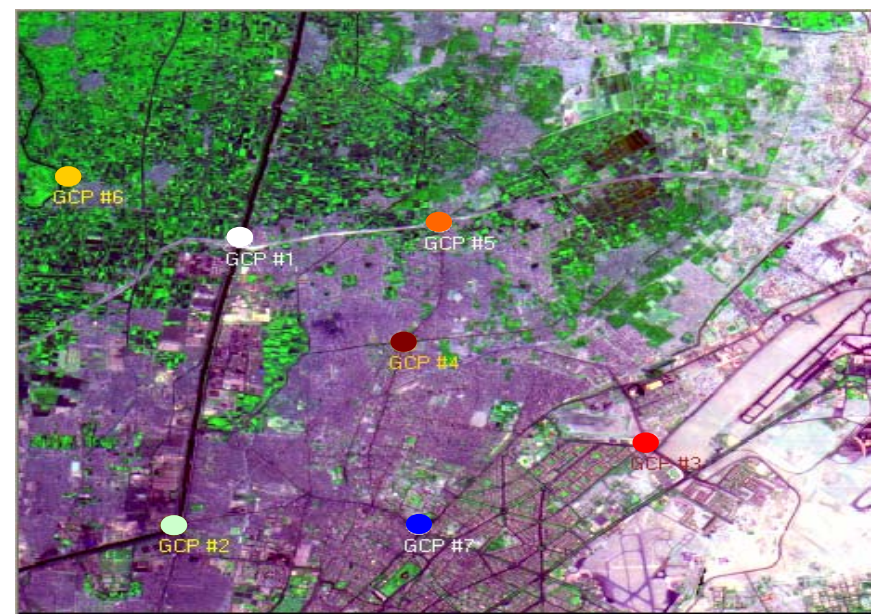

(c)

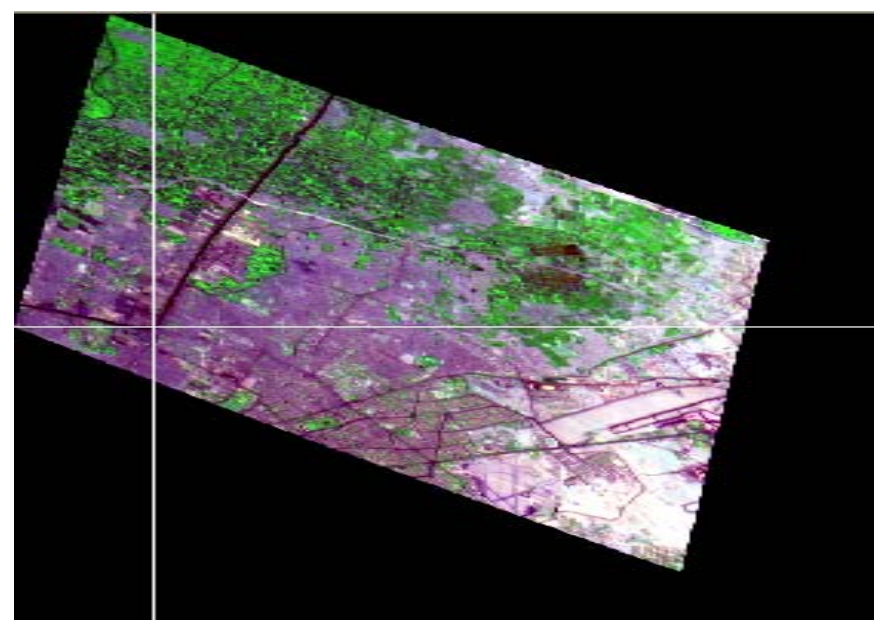

(e)

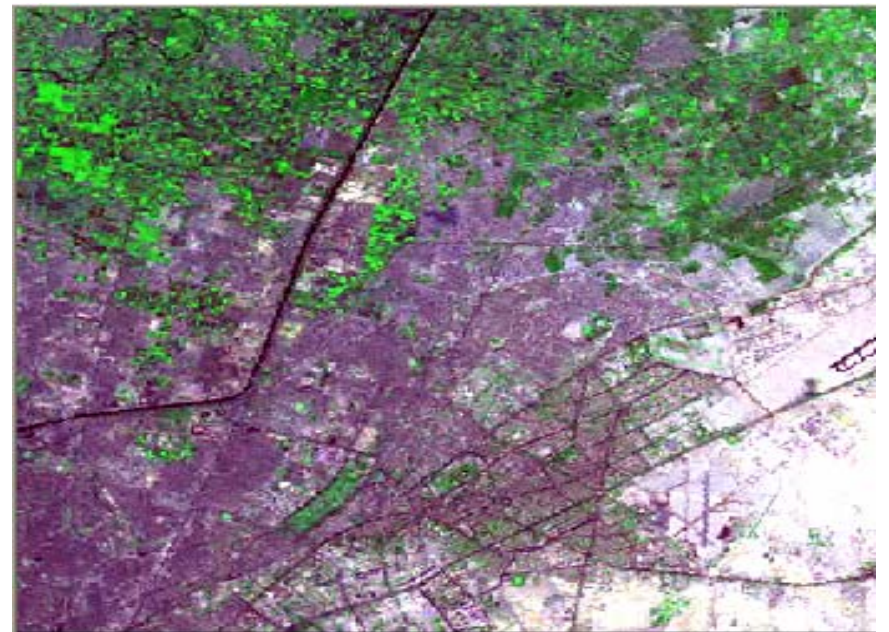

(b)

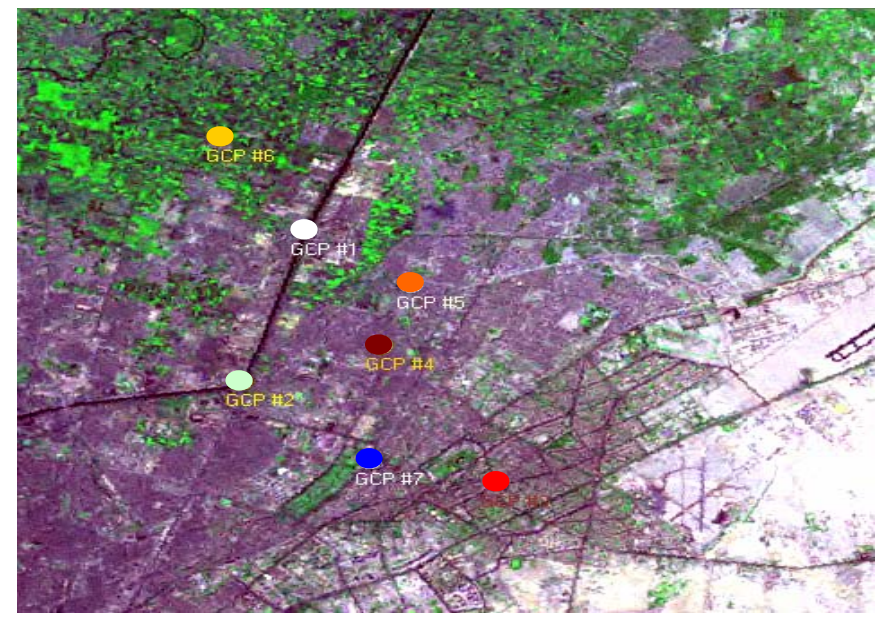

(d)

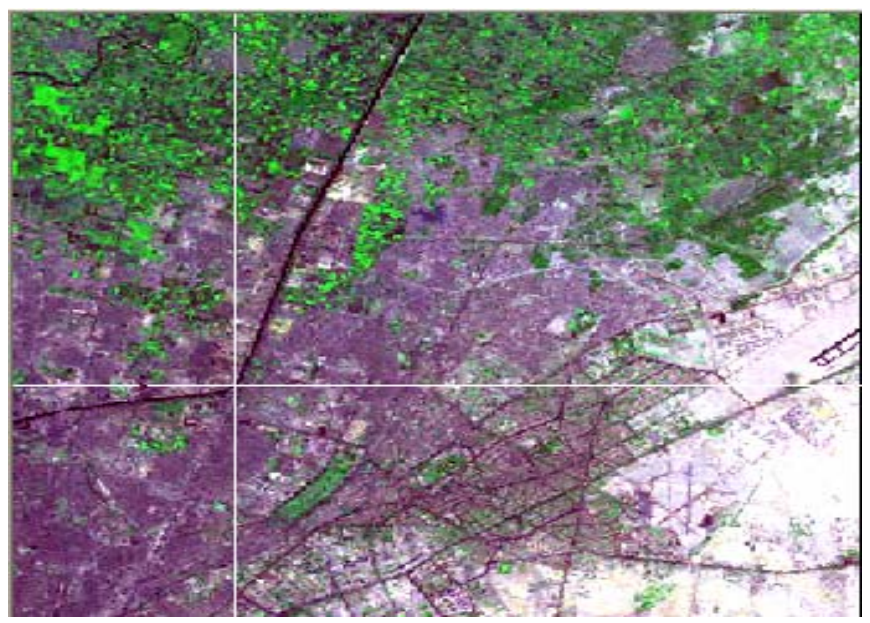

(f)

Fig. (12) a \& b - Raw image3 and its corresponding reference image, c \& d - 7 GCPs distribution on raw image 3 and its reference, e \& f - Corrected image3, and its reference with link between them. 
Proceedings of the $5^{\text {th }}$ ICEENG Conference, 16-18 May, 2006

$\mathrm{RE}-4-20$

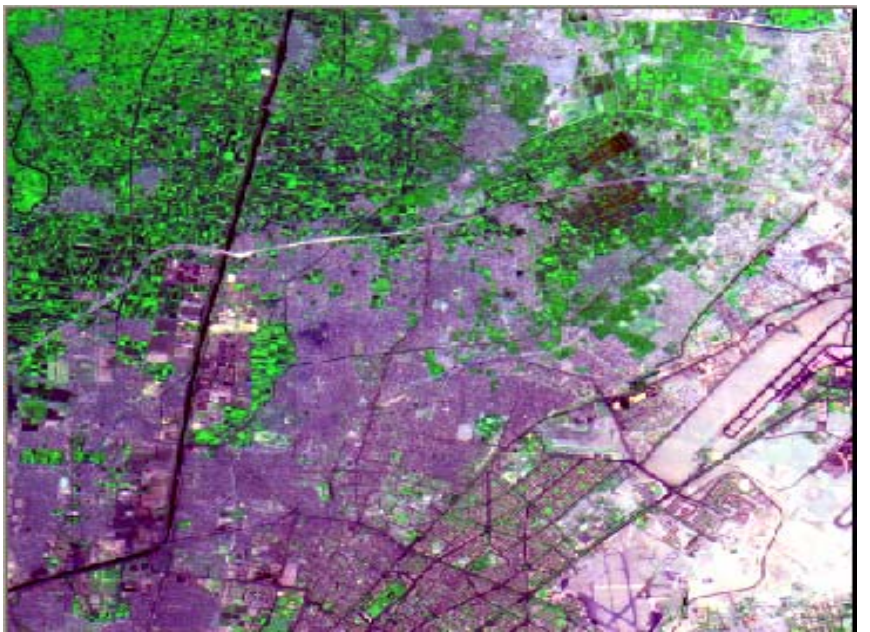

(a)

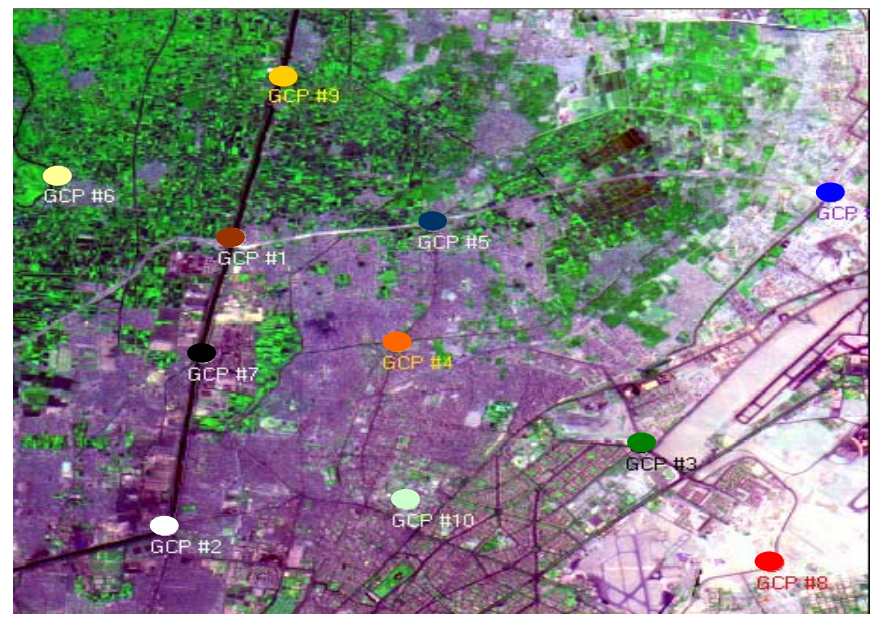

(c)

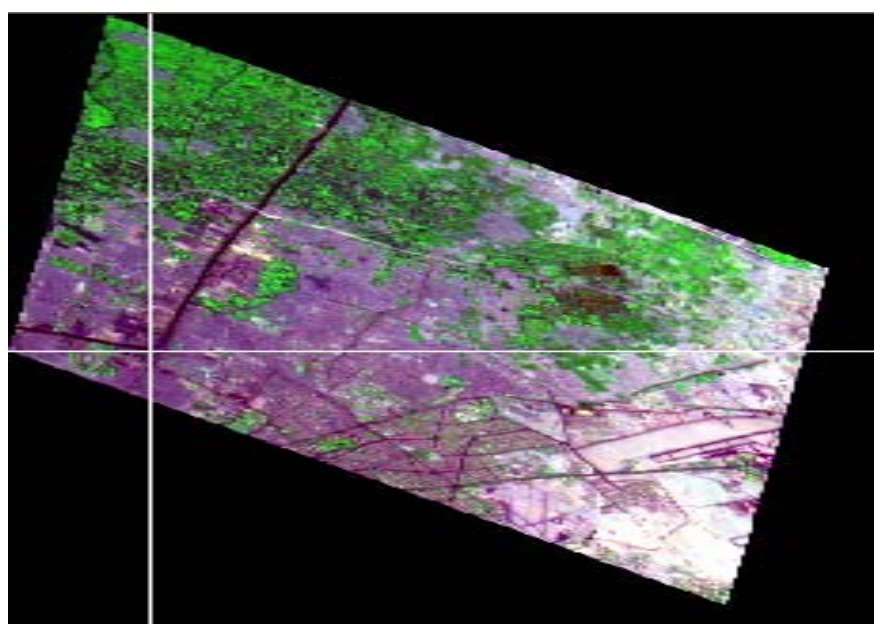

(e)

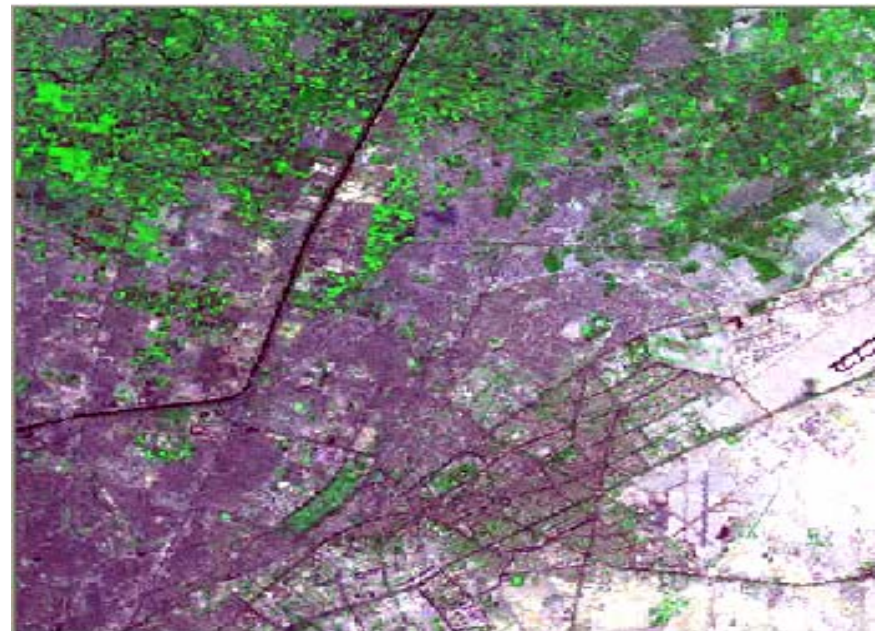

(b)

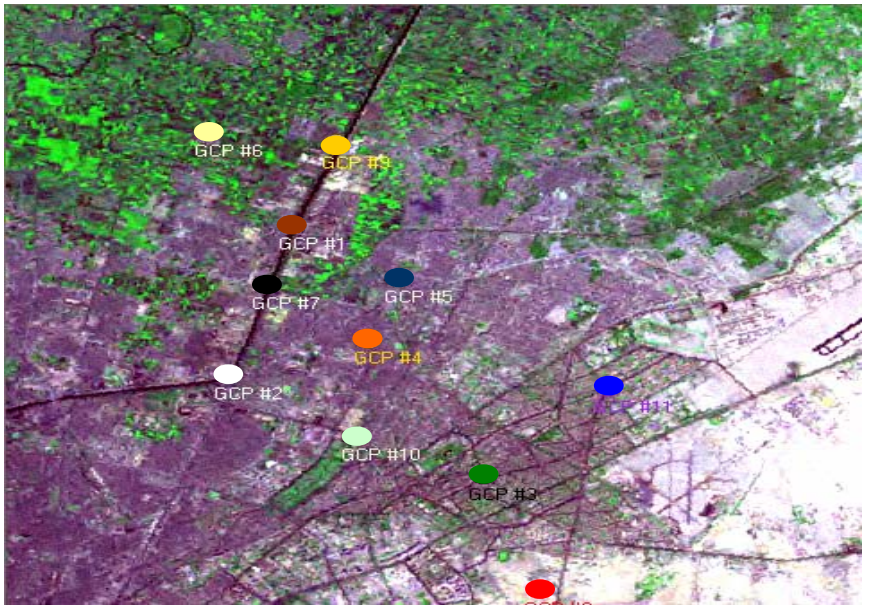

(d)

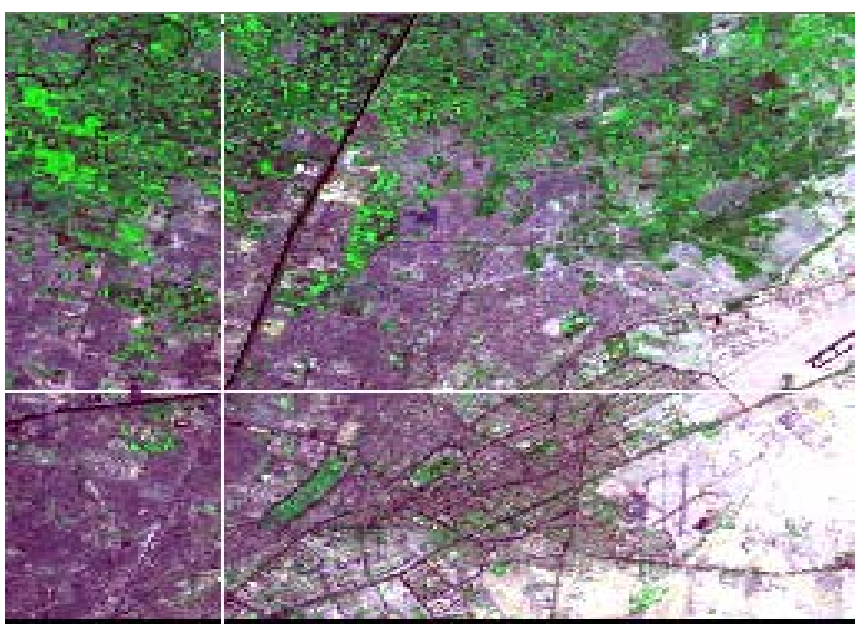

(f)

Fig. (13) a \& b - Raw image3 and its corresponding reference image, c \& d - 11 GCPs distribution on raw image3 and its reference, e \& f - Corrected image3, and its reference with link between them. 
Proceedings of the $\mathbf{5}^{\text {th }}$ ICEENG Conference, 16-18 May, 2006

$\mathrm{RE}-4-21$

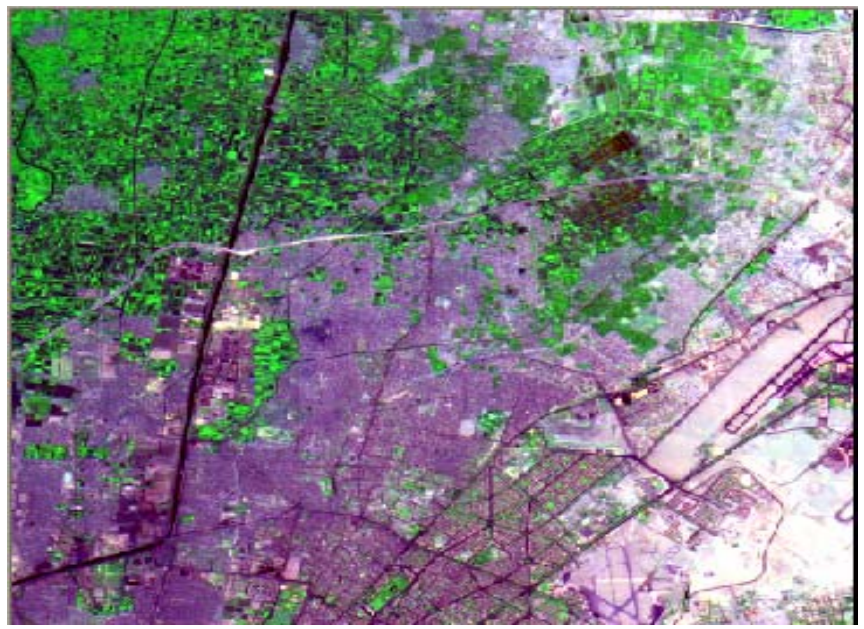

(a)

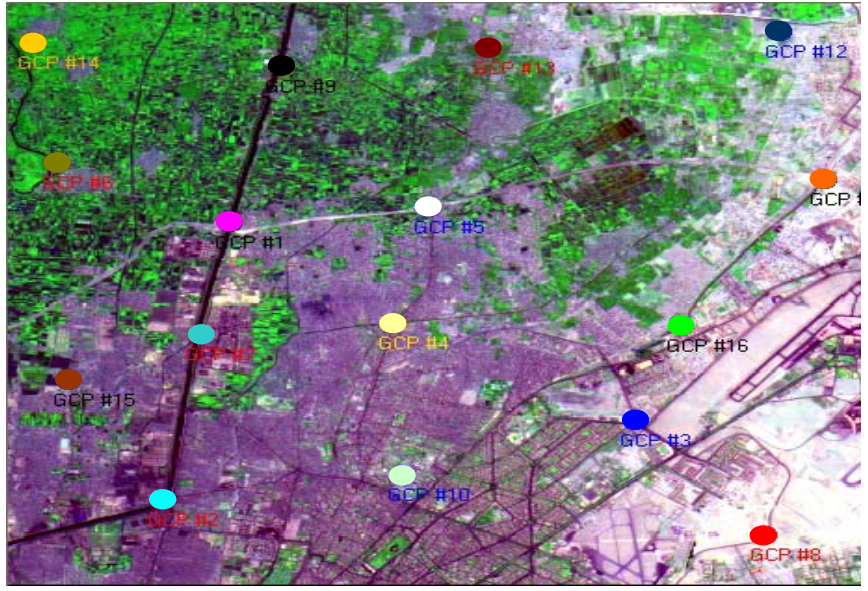

(c)

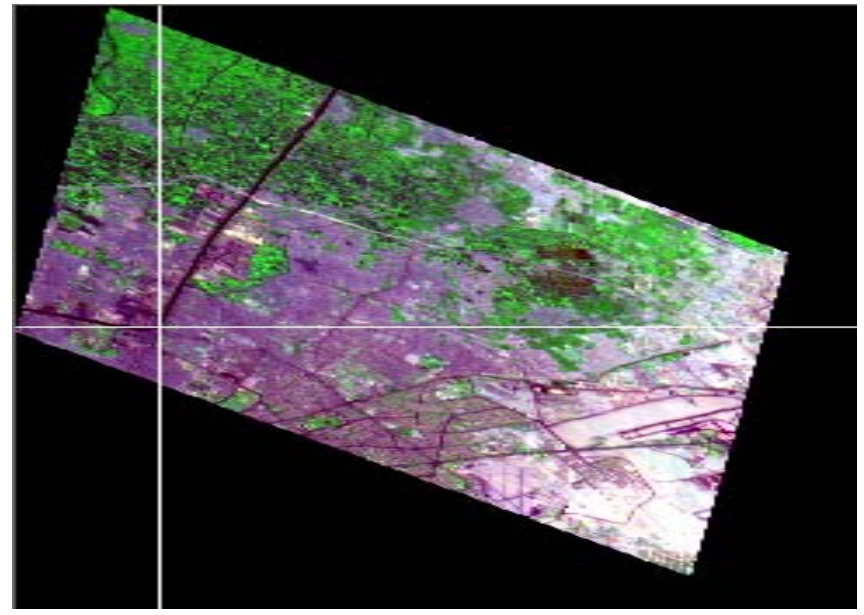

(e)

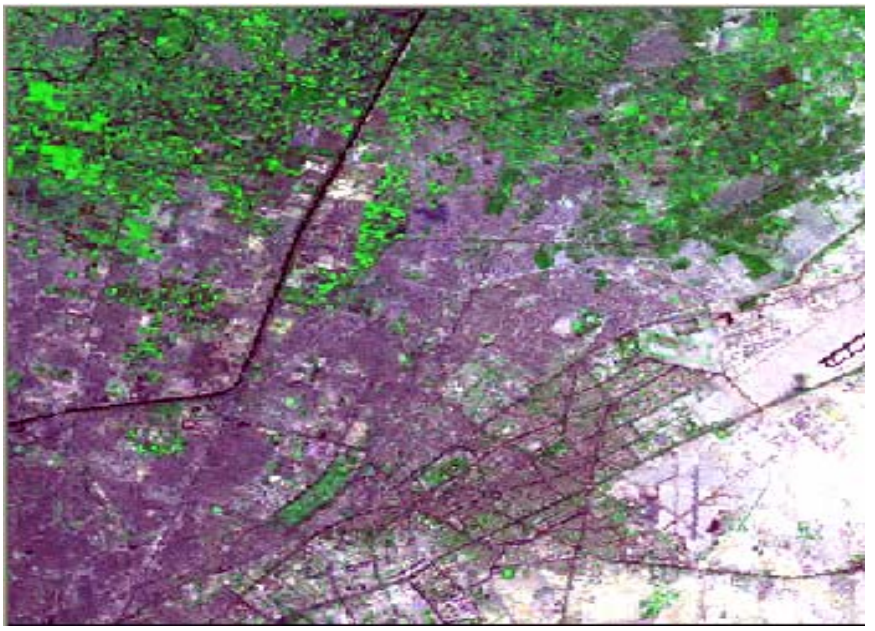

(b)

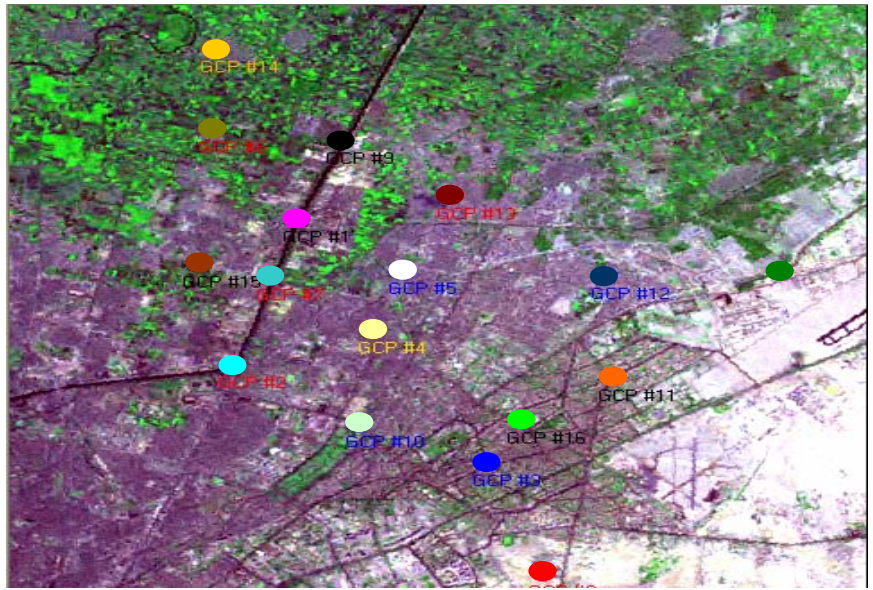

(d)

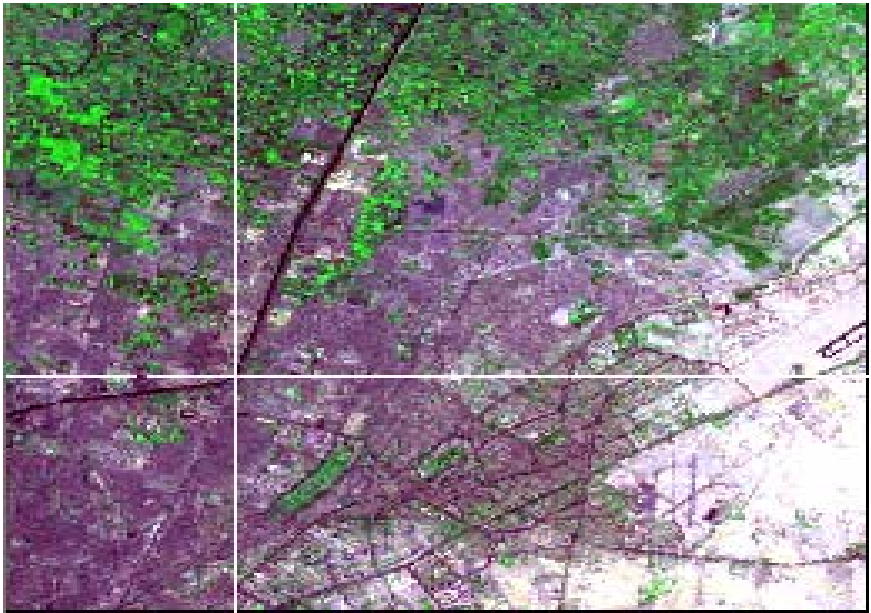

(f)

Fig. (14) a \& b - Raw image3 and its corresponding reference image, c \& d - 16 GCPs distribution on raw image3 and its reference, e \& f - Corrected image3, and its reference with link between them. 
Proceedings of the $\mathbf{5}^{\text {th }}$ ICEENG Conference, 16-18 May, 2006

$\mathrm{RE}-4-22$

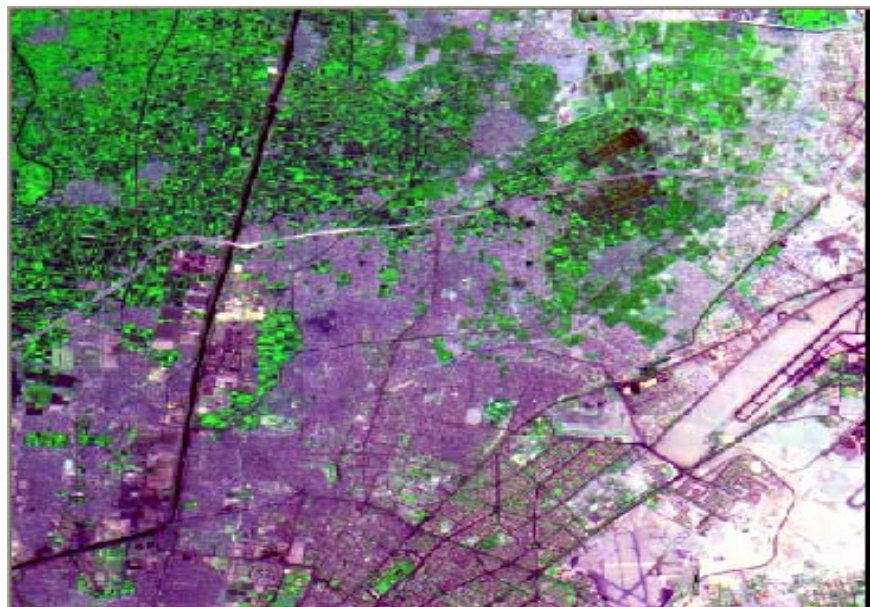

(a)

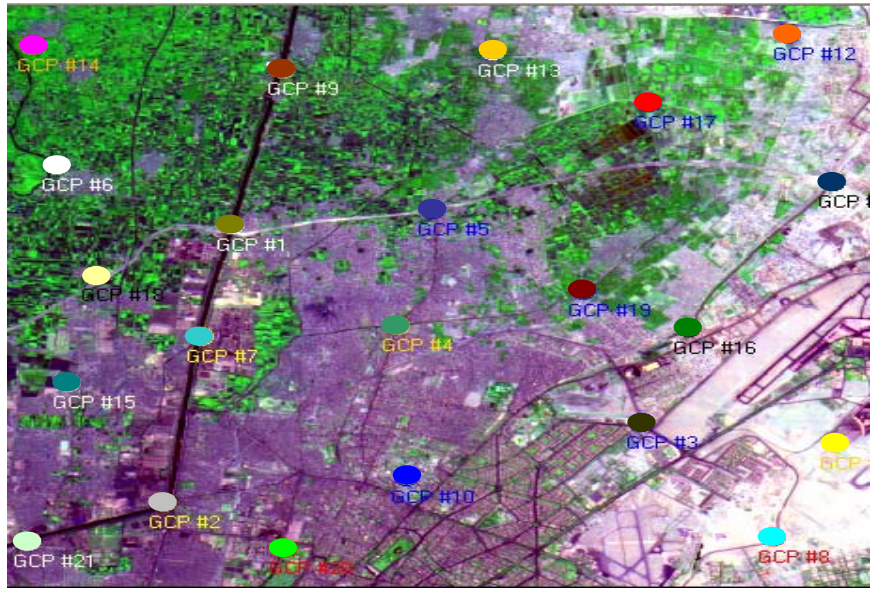

(c)

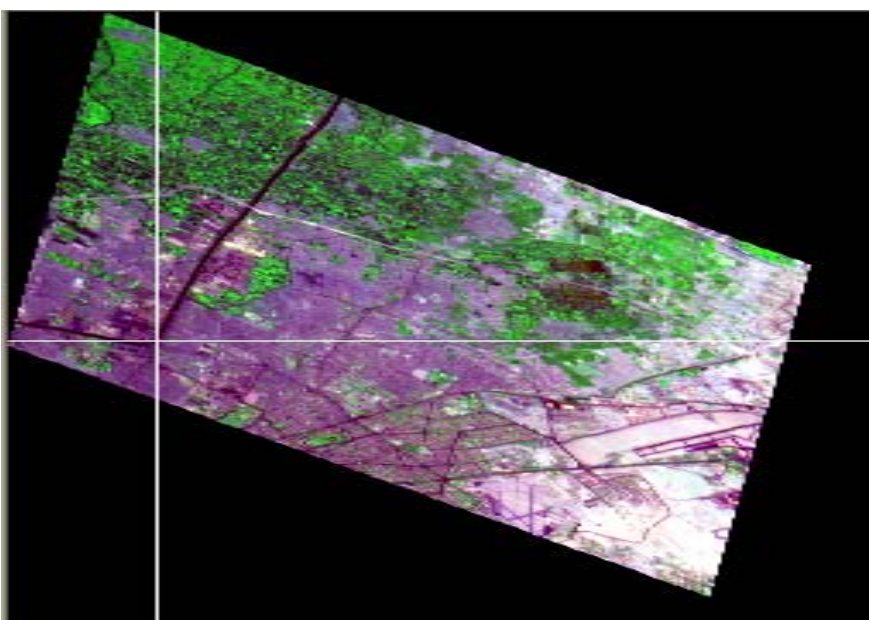

(e)

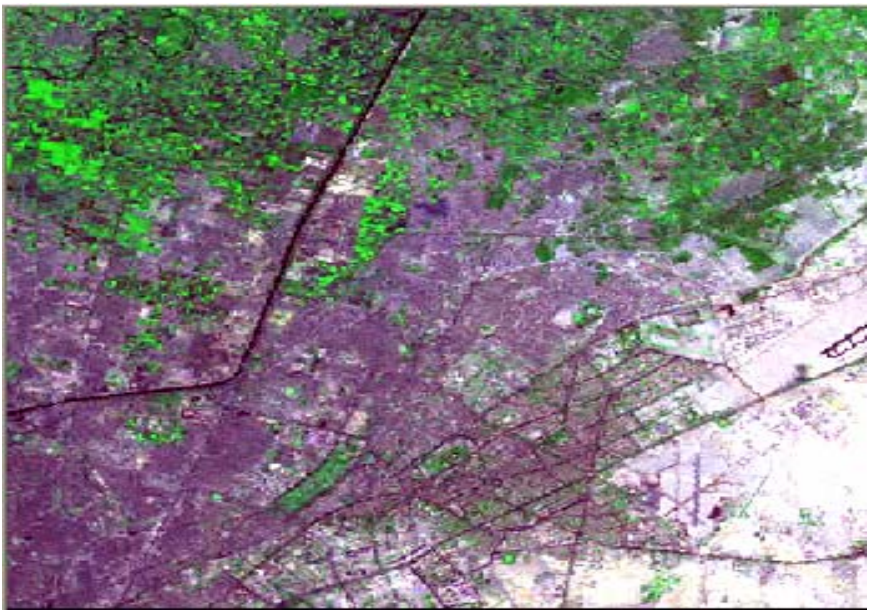

(b)

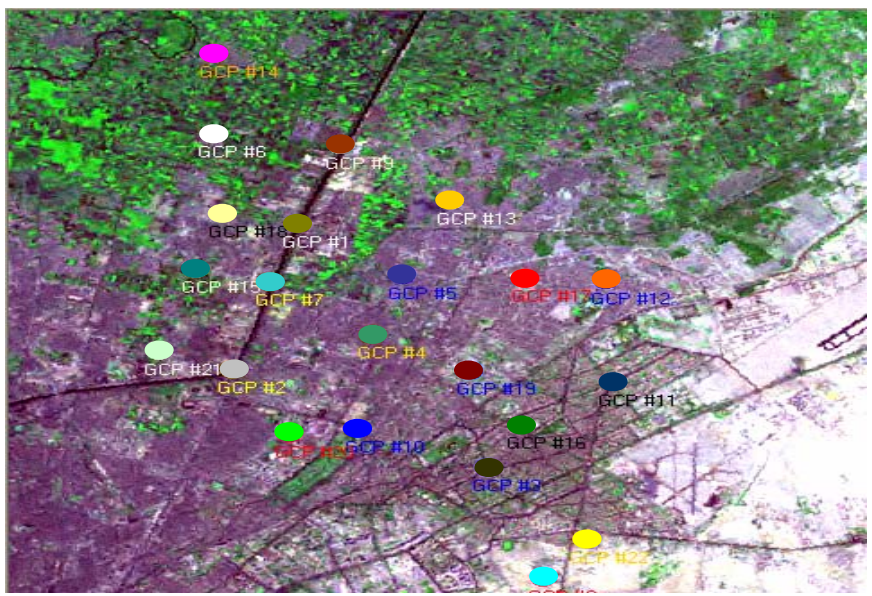

(d)

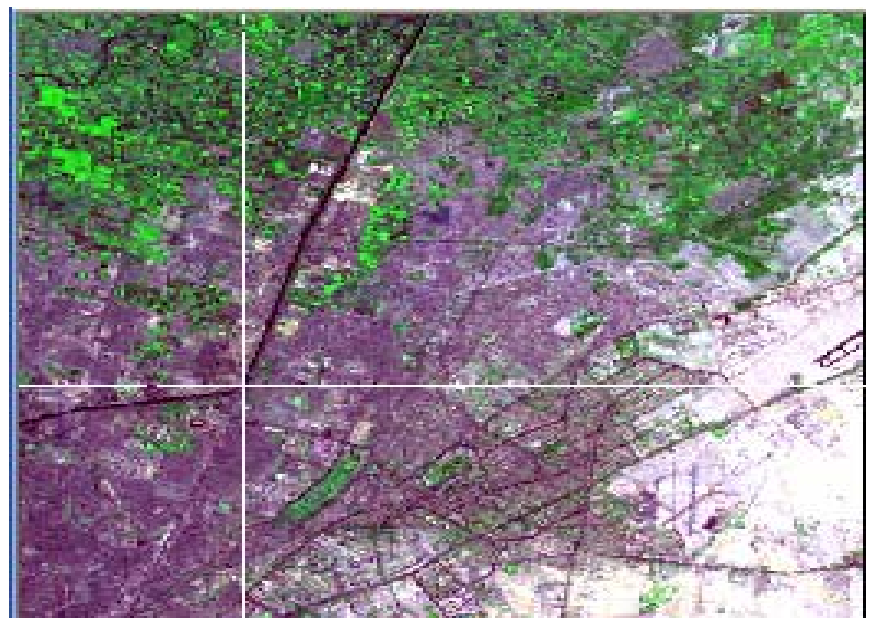

(f)

Fig. (15) a \& b - Raw image3 and its corresponding reference image, c \& d - 22 GCPs distribution on raw image3 and its reference, e \& f - Corrected image3, and its reference with link between them. 